\title{
Mixed-mode fracture evaluation of aerospace grade honeycomb core sandwich specimens using the Double Cantilever Beam-Uneven Bending Moment test method
}

\author{
Saseendran, Vishnu; Berggreen, Christian
}

Published in:

Journal of Sandwich Structures \& Materials

Link to article, DOI:

$10.1177 / 1099636218777964$

Publication date:

2020

Document Version

Peer reviewed version

Link back to DTU Orbit

Citation (APA):

Saseendran, V., \& Berggreen, C. (2020). Mixed-mode fracture evaluation of aerospace grade honeycomb core sandwich specimens using the Double Cantilever Beam-Uneven Bending Moment test method. Journal of Sandwich Structures \& Materials, 22(4), 991-1018 . https://doi.org/10.1177/1099636218777964

\section{General rights}

Copyright and moral rights for the publications made accessible in the public portal are retained by the authors and/or other copyright owners and it is a condition of accessing publications that users recognise and abide by the legal requirements associated with these rights.

- Users may download and print one copy of any publication from the public portal for the purpose of private study or research.

- You may not further distribute the material or use it for any profit-making activity or commercial gain

- You may freely distribute the URL identifying the publication in the public portal 


\title{
Mixed Mode Fracture Evaluation of Aerospace Grade Honeycomb Core Sandwich Specimens using the DCB-UBM Test Method
}

\author{
Vishnu Saseendran ${ }^{1}$ and Christian Berggreen ${ }^{1}$
}

\begin{abstract}
Fracture testing of aerospace grade honeycomb core sandwich composites is carried out using the Double Cantilever Beam specimen loaded with Uneven Bending Moments (DCB-UBM), and a DCB-UBM test rig capable of applying pure moments is utilized. Specimens with carbon fiber reinforced plastic (CFRP) face sheets are employed with a range of honeycomb core grades comprising of Nomex ${ }^{\circledR}$ and Kevlar paper. The sandwich specimens are reinforced with steel doublers to reduce excessive rotation of the face sheets. The mode mixity phase angle pertaining to a particular ratio of moments between the two arms of the DCB specimen is determined using the numerical mode mixity method - Crack Surface Displacement Extrapolation (CSDE) method. For Nomex ${ }^{\circledR}$ honeycomb core sandwich specimens, it is observed that the mode I interface fracture toughness increases with increase in core density. The interface fracture toughnesses for Nomex ${ }^{\circledR}$ based honeycomb cores is also compared against specimens with Kevlar paper-based honeycomb cores. Crack propagation is observed at the interface just beneath the meniscus layer for the majority of the tested specimen configurations. The DCB-UBM test methodology with the concept of direct application of moments on both crack flanks has proven to have a significant potential for mixed mode face/core fracture characterization of aerospace grade sandwich composites.
\end{abstract}

Keywords: DCB-UBM; Sandwich; Honeycomb; Nomex®; Face/core interface; Debond; CSDE

\section{Introduction}

Honeycomb core sandwich composites are widely used in aerospace industry and are employed in flight control surfaces as well as in several interior components. A crucial factor determining the integrity of a sandwich structure is the adhesive bonding between the face sheet and the core. The face/core debonding (or "disbonding") can be instigated through a bird strike, hail strike, blunt body impact or tool drop, as well as during the manufacturing phase due to insufficient wetting of face and core surfaces.

${ }^{1}$ Department of Mechanical Engineering, Technical University of Denmark, Nils

Koppels Allé, Building 404, 2800 Kgs. Lyngby, Denmark

\section{Corresponding Author:}

Vishnu Saseendran, Technical University of Denmark, 2800 Kgs. Lyngby, Denmark

E-mail:vsas@mek.dtu.dk 
The presence of debonds have led to several in-service failures ${ }^{1,2}$. In a debonded sandwich structure, the propensity of the crack to propagate through the interface or kink into the core is driven by the loading conditions. Therefore, the critical strain energy release rate required to separate the face from the core referred to as the fracture toughness, must be ascertained accurately in order to aid in design of sandwich structural components. The interface fracture toughness must be determined for a range of phase angles to serve as input into analysis models, as the load conditions may induce mode conditions varying from mode I to mode II and even mode III in some cases. As defined by Hutchinson and Suo ${ }^{17}$, the mode mixity phase angle, $\psi$, is the measure of mode II to mode I loading at the crack tip. In degrees, a pure mode I condition corresponds to $0^{\circ}$, and a pure mode II loading corresponds to $90^{\circ}$.

Many fracture mechanical methodologies exist to characterize face/core debonding. Prasad and Carlsson ${ }^{3,4}$ used the Double Cantilever Beam (DCB) test method to measure interface fracture properties in sandwich composites, but the inclination of the crack in a force loaded DCB test inherently depends on the face/core material system, and therefore kinking out of the interface is often in violation of the DCB sandwich test. The Tilted Sandwich Debond (TSD) test ${ }^{5}$ evolved from the DCB test for mode I fracture testing allows the sandwich specimen to be tilted, thereby ensuring crack propagation along the interface. However, within reasonable tilt angles only a limited range of mode mixity phase angles are possible for mixed mode face/core fracture characterization, even by reinforcing the face sheets with doubler layers ${ }^{6,7}$. The Single Cantilever Beam (SCB) specimen first discussed in ${ }^{8,9}$ is also gaining popularity for mode I fracture characterization owing to its simplicity. For mode II conditions, the Cracked Sandwich Beam (CSB) test, developed by Carlsson ${ }^{10}$ and End Notched Flexure (ENF) test introduced by Zenkert ${ }^{11}$ have been proposed. The Mixed Mode Bending (MMB) test is capable of face/core interface characterization under mixed mode conditions ${ }^{12,13}$. The sandwich SCB specimen is being considered to be developed as an ASTM International test standard for mode I fracture toughness assessment ${ }^{14}$. Initial sizing of the sandwich SCB specimen is detailed in ${ }^{15}$, in which the shear component at the crack tip is kept to a minimum based on kinematics of the SCB specimen. However, the mode mixity varies with crack length in a SCB specimen. In a sandwich MMB test, depending on the geometrical and material properties of the specimen, the lever arm distance may be adjusted to perform fracture testing at several mode mixity conditions 16. It should be noted that, as is the case with the TSD specimen, the possible range of mode mixity phase angle $(\psi)$ in a MMB test is limited.

A mixed-mode fracture specimen, known as the Double Cantilever Beam loaded with Uneven or unequal Bending Moments (DCB-UBM), capable of achieving a wide array of mode mixity conditions was first introduced by Sørensen et al. ${ }^{18}$ for laminates, and was later to extended to sandwich composites by Lundsgaard-Larsen et al. in ${ }^{19}$. A schematic illustration of the sandwich DCB-UBM specimen is shown in Figure 1, in which pure moments are applied to both crack flanks. For a fixed moment ratio $\left(M R=M_{1} / M_{2}\right)$, the mode mixity phase angle $(\psi)$ 
remains constant. Therefore, by holding the moment ratio $(M R)$ constant throughout the crack propagation during the fracture testing, toughness characterization can be performed at a fixed phase angle $(\psi)$. Closed form expressions for both energy release rate and mode mixity phase angle for an un-reinforced (see Figure 1a) ${ }^{20}$ and reinforced (Figure 1b) ${ }^{21}$ sandwich DCB-UBM specimens exist in the literature. Attachment of reinforcement layers, referred to as "doublers", on both sides of the specimen reduces excessive rotations and displacements, especially for specimens with thin face sheets ${ }^{22}$.

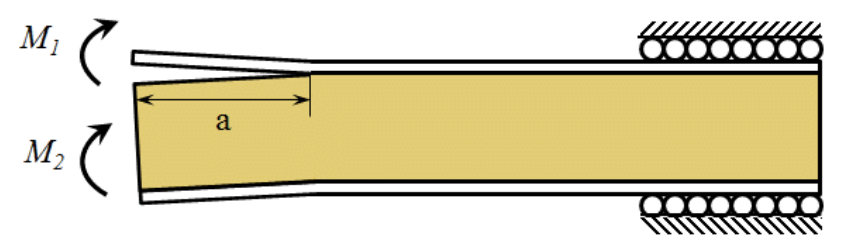

(a)

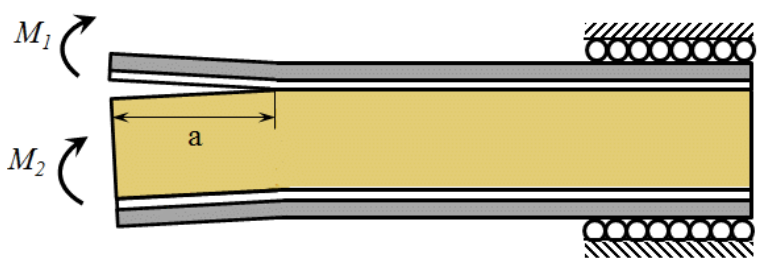

(b)

Figure 1. Schematic illustration of the sandwich DCB-UBM specimen (a) un-reinforced (b) reinforced with doubler layers.

Face/core fracture toughness measurements under predominant mode I conditions of honeycomb cored sandwich specimens were previously conducted using the DCB and SCB test methods ${ }^{23,24}$. The objective of this paper is to perform mixed mode fracture characterization of honeycomb cored sandwich specimens using the DCB-UBM test method. The fracture testing was carried out in a novel test rig in which the moments were applied using independent torsional actuators. In order to understand the influence of core density, cell-size and core paper properties on the fracture toughness, four different classes of sandwich systems were analyzed. A detailed discussion of materials and specimen preparations are provided in the subsequent section.

\section{Materials, Specimen Preparation and Test Method}

\section{Specimen preparation and material characterization}

The sandwich specimens studied in this work consisted of aerospace grade honeycomb cores manufactured by Schütz GmbH. Two core types - Cormaster C1 ${ }^{25}$ comprising of Nomex® T412 paper and Cormaster N636 ${ }^{26}$ made of para-aramid Kevlar N636 paper were considered. Three density classes of the Cormaster C1 type (32, 64 and $\left.96 \mathrm{~kg} / \mathrm{m}^{3}\right)$ and one density class (32 $\mathrm{kg} / \mathrm{m}^{3}$ ) of the Cormaster N636 were investigated. A plain weave Carbon Fiber Reinforced Plastic (CFRP) prepreg (Hexcel fabric with HexPly®913 epoxy resin) manufactured by Hexcel corporation ${ }^{27}$ was chosen as face sheets with two stacking sequences - $\left[\left(0^{\circ} / 90^{\circ}\right)\right]$ and $\left[\left( \pm 45^{\circ}\right) /\right.$ $\left.\left(0^{\circ} / 90^{\circ}\right) /\left(0^{\circ} / 90^{\circ}\right) /\left( \pm 45^{\circ}\right)\right]$. A plain weave fabric laminate with a stacking sequence $\left[\left( \pm 45^{\circ}\right) /\right.$ 
$\left.\left(0^{\circ} / 90^{\circ}\right) /\left(0^{\circ} / 90^{\circ}\right) /\left( \pm 45^{\circ}\right)\right]$, where $\left( \pm 45^{\circ}\right)$ or $\left(0^{\circ} / 90^{\circ}\right)$ is a layer, can be considered as symmetrically stacked ${ }^{28}$. The nominal cured thickness of the CFRP prepreg was $0.35 \mathrm{~mm}$.

The DCB-UBM specimens $(450$ x $60 \mathrm{~mm})$ were cut from sandwich panels which were manufactured at the Airbus Stade facility. An AF163 film adhesive ${ }^{29}$ was used to adhere the face sheets onto the core. The sandwich panels were vacuum bagged and cured with a one shot curing (co-curing) cycle under $2 \mathrm{Bar}$ pressure in an autoclave. The panel used a $125^{\circ} \mathrm{C}$ curing system. The adhesive film had no contribution the thickness of the face sheet and formed only the meniscus layer. DCB-UBM specimens $(450 \times 60 \mathrm{~mm})$ were cut from each cured sandwich panel using a diamond cutter and doubler layers were glued, see Figure 2.

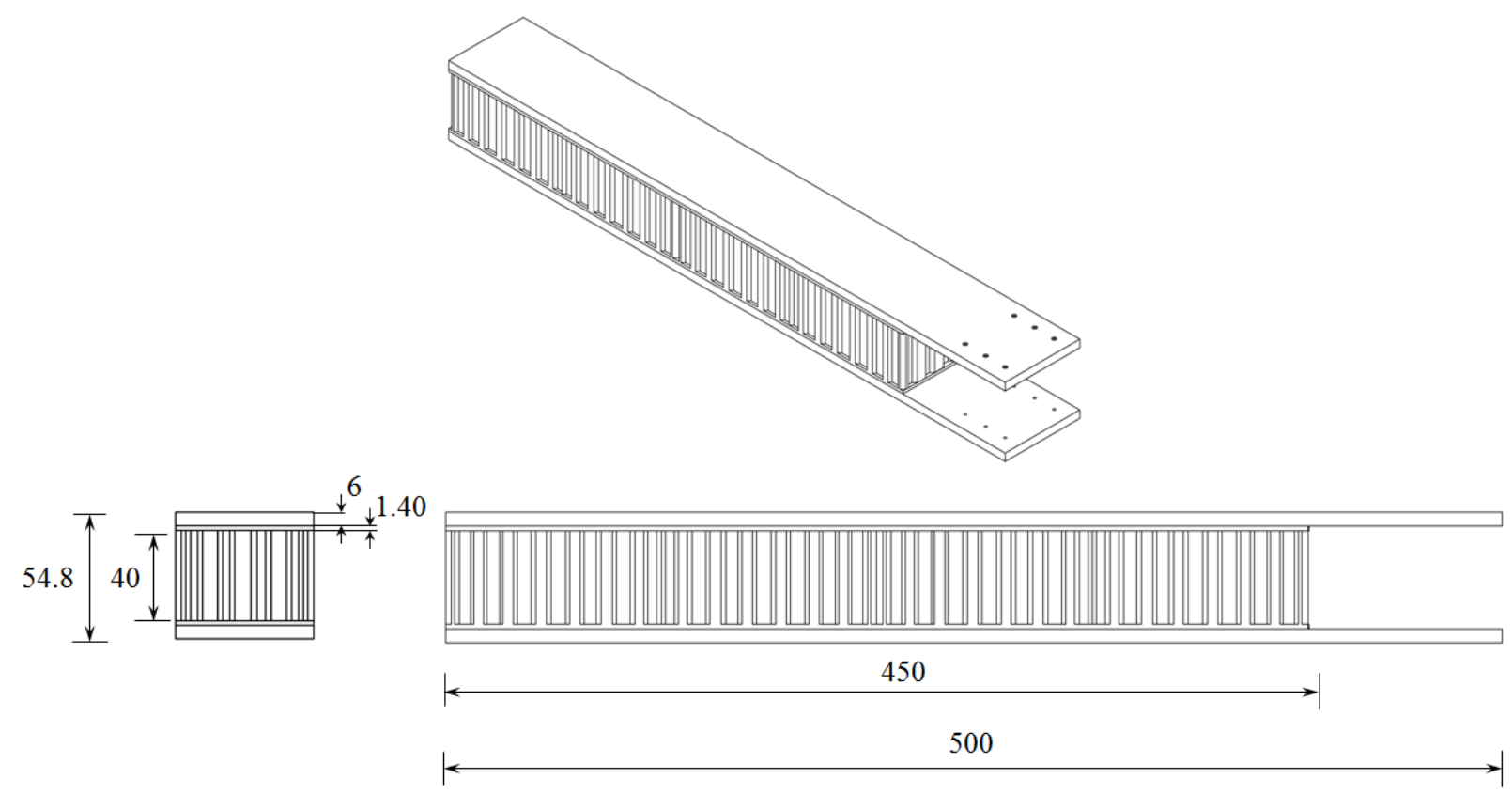

Figure 2. DCB-UBM specimen dimensions (in $\mathrm{mm}$ ).

The DCB-UBM specimens were bonded to reinforcement layers to prevent excessive rotation of thin face sheets. Adhesion of such "doubler" material restrict the fracture analysis to be in the Linear Elastic Fracture Mechanics (LEFM) regime by preventing excessive crack tip distortions ${ }^{22}$. The doublers were chosen in this study such that they do not undergo yielding during fracture testing. A high strength Uddeholm IMPAX SUPREME $®$ steel ${ }^{30}\left(E=210 \mathrm{GPa}, \sigma_{Y}=900 \mathrm{MPa}\right)$ with a thickness of $6 \mathrm{~mm}$ was used throughout. The steel doublers were bonded to the specimens using 3M DP460 epoxy glue ${ }^{31}$, and was cured at room temperature for a duration of 24 hours. Clamps were employed to achieve even glue thickness and to prevent misalignment, see Figure 3(a). The prepared specimens are shown in Figure 3(b). 


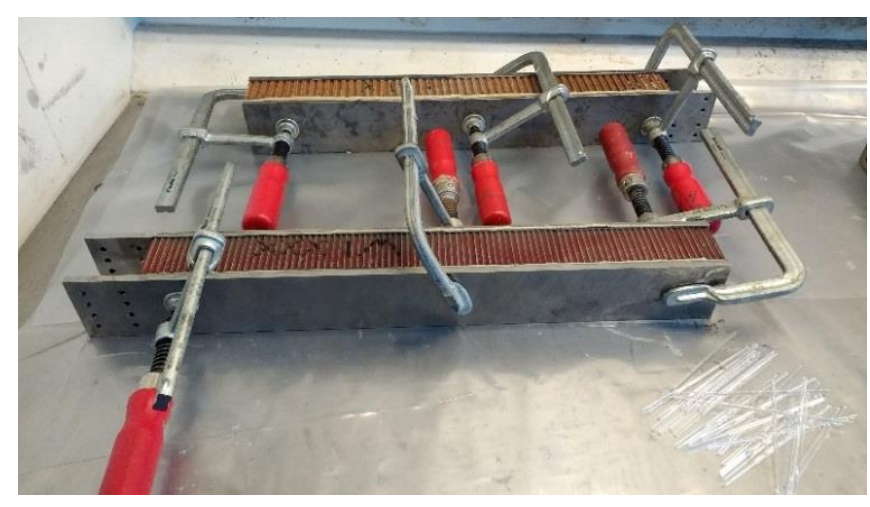

(a)

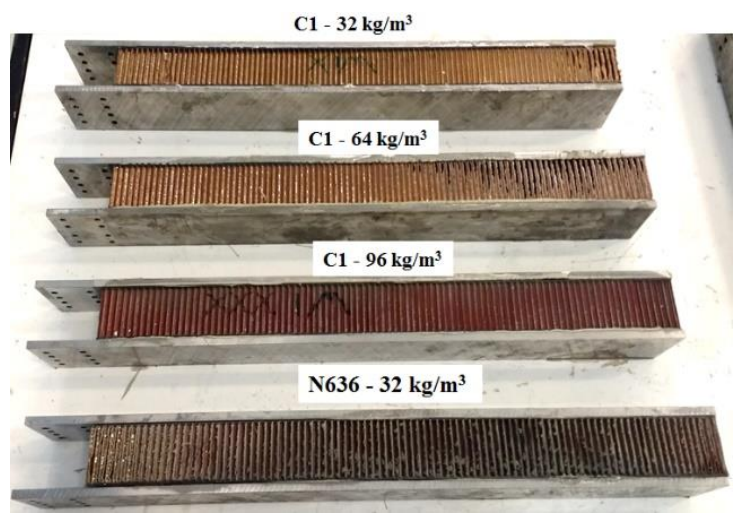

(b)

Figure 3. Preparation of reinforced DCB-UBM specimens: (a) Adhesion of doubler layers to specimens with the aid of clamps, (b) prepared DCB-UBM specimens with doublers.

In this study, the influence of core density, crack propagation direction, face sheet thickness and paper material properties on the fracture toughness were investigated. Thus, a total of twenty specimens were tested including specimens with two face sheet thicknesses $\left(h_{f}=0.35 \mathrm{~mm}\right.$ and $1.4 \mathrm{~mm}$ ), three core densities $\left(32,64\right.$ and $96 \mathrm{~kg} / \mathrm{m}^{3}$ ), and two core paper materials (Nomex® T412 and Kevlar N636). The core thickness was constant throughout out the analysis, $h_{c}=40$ $\mathrm{mm}$. The material properties of the face sheets were determined using ASTM standard tests ${ }^{32,33}$ at Fraunhofer IMWS, Halle ${ }^{34}$. The steel properties were obtained from technical data sheet ${ }^{30}$. The face sheet and doubler material properties are provided in Table 1, where index 1 refers to $0^{\circ}$ direction, and index 2 refers to the transverse direction.

Table 1. Material properties for face sheet and steel doubler ${ }^{30,34,35}$.

\begin{tabular}{|c|c|c|c|c|c|}
\hline \multicolumn{2}{|c|}{$\begin{array}{c}\text { Face sheet } \\
{\left[\left(0^{\circ} / 90^{\circ}\right)\right]} \\
\boldsymbol{h}_{f}=\mathbf{0 . 3 5} \mathbf{~ m m}\end{array}$} & \multicolumn{2}{|c|}{$\begin{array}{c}\text { Face sheet } \\
{\left[\left( \pm 45^{\circ}\right) /\left(0^{\circ} / 90^{\circ}\right) /\left(0^{\circ} / 90^{\circ}\right) /\left( \pm 45^{\circ}\right)\right]} \\
h_{f}=1.40 \mathrm{~mm}\end{array}$} & \multicolumn{2}{|c|}{$\begin{array}{c}\text { Doubler layer } \\
\text { (Steel) } \\
h_{r}=\mathbf{6 . 0} \mathbf{~ m m}\end{array}$} \\
\hline $\mathrm{E}_{11}[\mathrm{GPa}]$ & 63.20 & $\mathrm{E}_{11}[\mathrm{GPa}]$ & 49.30 & $\mathrm{E}_{\mathrm{r}}[\mathrm{GPa}]$ & 210 \\
\hline $\mathrm{E}_{22}[\mathrm{GPa}]$ & 48.10 & $\mathrm{E}_{22}[\mathrm{GPa}]$ & 47.00 & $v_{r}$ & 0.30 \\
\hline $\mathrm{G}_{12}[\mathrm{GPa}]$ & 5.27 & $\mathrm{G}_{12}[\mathrm{GPa}]$ & 1.84 & & \\
\hline$v_{12}$ & 0.0539 & $v_{12}$ & 0.3159 & & \\
\hline
\end{tabular}

The honeycomb core material properties were estimated using the analytical expressions derived by Gibson and Ashby ${ }^{36}$ for cellular materials. The original expressions in ${ }^{36}$ were expanded to a wide range of honeycombs in ${ }^{37}$ by proposing more accurate expressions based on both analytical and numerical approaches. These expressions can be applied to typical 
honeycomb cores with double cell walls, such as the ones used in this study and require elastic constants of the honeycomb paper material as input. The paper properties of the various core types investigated here were measured at TU Dresden ${ }^{38}$. A detailed description of measurement of the core paper properties can be found in ${ }^{38}$. The honeycomb core properties are provided in Table 2. It should be noted that for all the core types considered in this paper, the cell size and core thickness were $4.8 \mathrm{~mm}$ and $40 \mathrm{~mm}$ respectively. Figure 4 provides a schematic illustration of cell size and cell wall thicknesses, where $\mathrm{T}$ refers to the cell thickness direction, $\mathrm{L}$ - ribbon direction and $\mathrm{W}-$ transverse direction. For brevity, the honeycomb core is designated as core type - cell size - density throughout this paper, e.g. C1-4.8-32 refers to Cormaster C1 type core with a $4.8 \mathrm{~mm}$ cell size and a density of $32 \mathrm{~kg} / \mathrm{m}^{3}$. The N636 core type is referred to as CN1.

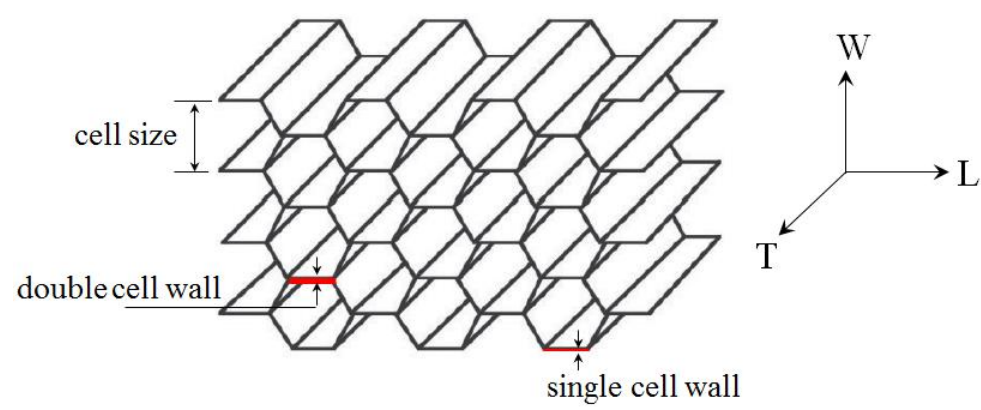

Figure 4. Schematic illustration of a typical hexagonal honeycomb core cell.

Table 2. Material properties for honeycomb cores ${ }^{37,38}$.

\begin{tabular}{|l|c|c|c|c|}
\hline & C1-4.8-32 & C1-4.8-64 & C1-4.8-96 & CN1-4.8-32 \\
\hline $\mathrm{E}_{\mathrm{L}}[\mathrm{MPa}]$ & 0.075 & 0.226 & 0.492 & 0.104 \\
$\mathrm{E}_{\mathrm{W}}[\mathrm{MPa}]$ & 0.075 & 0.226 & 0.492 & 0.104 \\
$\mathrm{E}_{\mathrm{T}}[\mathrm{MPa}]$ & 121.9 & 176.3 & 228.5 & 298.1 \\
$\mathrm{G}_{\mathrm{LW}}[\mathrm{MPa}]$ & 0.033 & 0.010 & 0.022 & 0.092 \\
$\mathrm{G}_{\mathrm{TL}}[\mathrm{MPa}]$ & 20.7 & 29.9 & 38.7 & 59.6 \\
$\mathrm{G}_{\mathrm{TW}}[\mathrm{MPa}]$ & 13.1 & 18.9 & 24.5 & 35.9 \\
$v_{\mathrm{LW}}$ & 1.0 & 1.0 & 1.0 & 1.0 \\
$v_{\mathrm{TL}}$ & 0.354 & 0.36 & 0.354 & 0.354 \\
$v_{\mathrm{TW}}$ & 0.350 & 0.35 & 0.350 & 0.354 \\
Density $\left[\mathrm{kg} / \mathrm{m}^{3}\right]$ & 32 & 64 & 96 & 32 \\
Paper thickness, $\mu \mathrm{mm}$ & 56 & 81 & 105 & 62 \\
(single cell wall) & & & & \\
\hline
\end{tabular}




\section{DCB-UBM Test Procedure}

In the DCB-UBM test method pure moments are applied to the specimen edges or crack flanks, see Figure 1. Thus, the mode mixity can be altered by changing the ratio of the applied moments, $M R=M_{1} / M_{2}$. As the moment ratio, $M R$, is held constant throughout the test, the DCB-UBM test methodology is characteristically a steady-state fracture specimen. Hence, both energy release rate, $G$, and mode mixity expressed as phase angle, $\psi$, remain constant throughout the crack propagation. The original test rig introduced by Sørensen et al. ${ }^{18}$ applied moments to the crack flanks using long wires. A new test rig capable of applying moments directly on the crack flanks through independent torsional actuators ${ }^{39}$ was used in the current study. A honeycomb cored sandwich specimen mounted in the new test set up prior to testing is shown in Figure 5. Loading tabs are screwed to the doubler ends which is then slid between load arm clamps, see Figure 5. Here, the doublers also help in application of moments through loading arms. The width of clamp support was adjusted to account for the specimen thickness. The clamp support contains rollers which enable sliding of the specimen in its longitudinal direction. The new test rig is capable of achieving a wide range of moment ratios $(M R)$. Moreover, the current rig is capable of applying moments up to $250 \mathrm{Nm}$, with a provision to hiking the capacity up to $500 \mathrm{Nm}^{39}$.

A MTS FlexTest ${ }^{\mathrm{TM}}$ SE ${ }^{40}$ controller was used to maintain the fixed moment ratio, $M R$, throughout the test to ensure that the test is conducted at a constant mode mixity condition. The control algorithm was programmed such that, when rotation is applied to arm-1, arm-2 follows arm-1 to satisfy a pre-defined moment ratio; $M_{2}=M_{1} / M R$ (see Figure 5). The direction of rotation of each arm can be altered such that: a) both arms open relative to each other b) rotate in clock-wise direction with respect to plane of paper or c) rotate in counter clock-wise direction. The selection of $M R$ pertaining to a particular mode mixity condition for a particular sandwich configuration was obtained numerically. The mode mixity expressed as phase angle $(\psi)$, was obtained using the numerical mode separation method - Crack Surface Displacement Extrapolation Method (CSDE) ${ }^{41}$. A detailed description of the selection of a $M R$ to obtain a specific phase angle $(\psi)$, is provided in Appendix A. A pre-crack length of $50 \mathrm{~mm}$ was introduced at the face/core interface of each specimen using a band-saw. This procedure enabled introduction of the crack along the face/core interface just beneath the meniscus layer. To produce a clean crack front, the crack front was further sharpened by using a very thin razor blade. It should be noted that, the pre-crack position for all the tested configurations in this paper lies below the meniscus layer. The pre-crack may also be positioned between the face sheet and core using a Teflon ${ }^{\circledR}$ film. Depending on the constituent face/core material system, the crack might propagate along the path of the least resistance, which in this case could be between the face sheet and meniscus layer; provided the meniscus layer is tough enough to prevent the crack from penetrating at higher positive mode mixity phase angle values. 


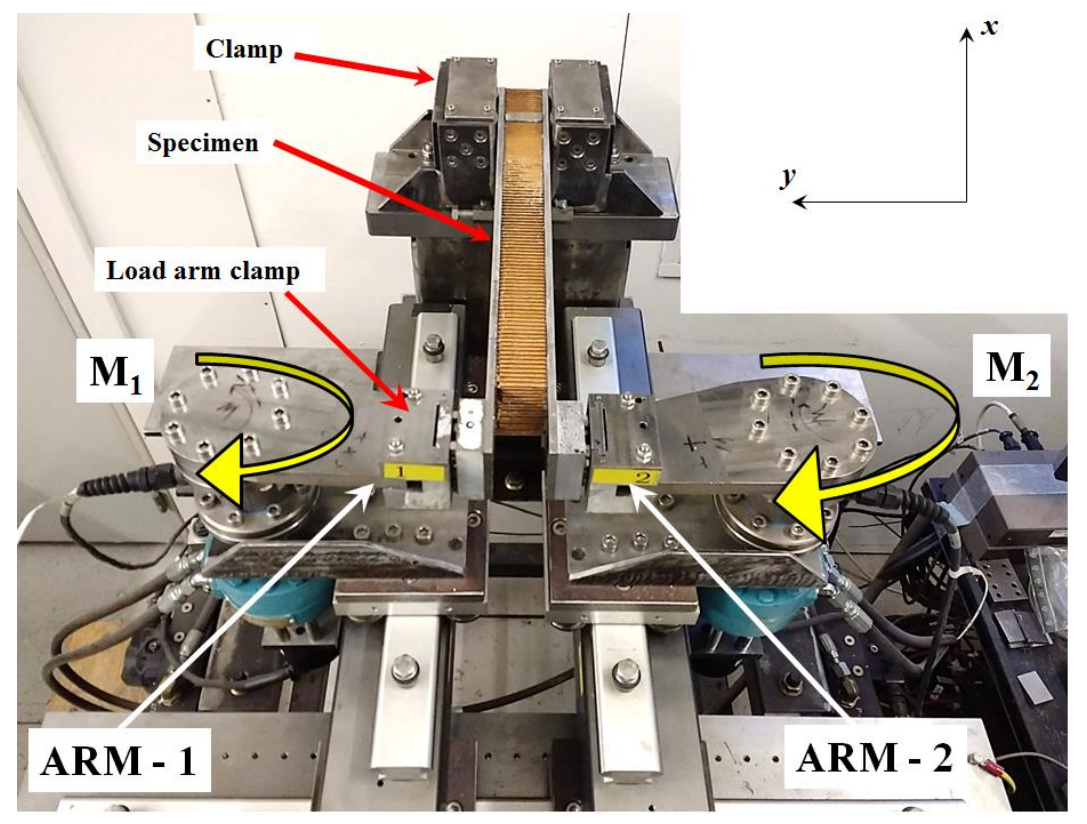

Figure 5. DCB-UBM test rig with a honeycomb core sandwich specimen held between both arms prior to testing.

All specimens were loaded in rotation control at a quasi-static rate of $10 \% / \mathrm{min}$. The loading was continued until the disbond grew by $\sim 10 \mathrm{~mm}$ (approximately two cells), following which the specimens were un-loaded manually. The crack propagation in a DCB-UBM specimen occurs at constant mode mixity. Therefore, a single specimen may be employed to perform fracture characterization at multiple mode mixity conditions.

Rotation $(\theta)$ and moment $(M)$ of both arms were continuously logged during each load cycle at a fixed rate of $5 \mathrm{~Hz}$. The crack increment of each loading cycle was marked on the doubler edges. It should be noted that the energy release rate in a DCB-UBM specimen is independent of crack length. Therefore, accurate monitoring of the crack front using high resolution cameras is not required as opposed to other test methods such as the DCB, SCB or MMB. Moreover, the crack initiation can be noted from the deviation in slope in the $M$ vs. $\theta$ plot. The detailed data reduction procedure is outlined in the next section. 


\section{Data Reduction Method}

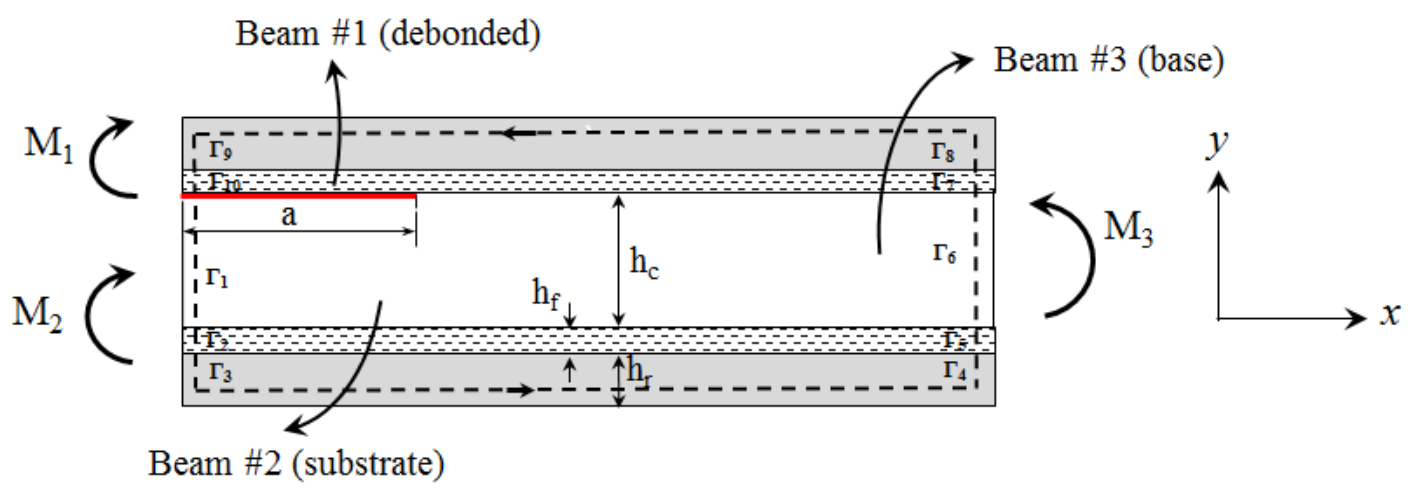

Figure 6. $J$-integral path in the DCB-UBM sandwich specimen reinforced with steel doubler layers.

The recorded moments were used to compute the energy-release rate, and the fracture analysis was carried out under the ambit of the LEFM regime. For a DCB-UBM sandwich specimen reinforced with doubler layers, the energy-release rate can be expressed using the path independent $J$-integral ${ }^{42}$, derived by Lundsgaard et al. ${ }^{19}$ as:

$$
J=\sum_{p=1}^{10} \frac{\bar{E}_{p} M_{b}^{2}}{6\left(A_{b} D_{b}-B_{b}^{2}\right)^{2}}\left[A_{b}^{2}\left(y_{p-1}^{3}-y_{p}^{3}\right)-3 A_{b} B_{b}\left(y_{p-1}^{2}-y_{p}^{2}\right)+3 B_{b}^{2}\left(y_{p-1}-y_{p}\right)\right]
$$

where $A, B$ and $D$ are extensional, bending and coupling terms. The subscript " $b$ " refers to each beam, whilst " $p$ " refers to the path evaluated using the $J$-integral (Equation 1), as shown in Figure 6. It can be noted in Equation (1) that the energy-release rate is independent of the crack length, and depends on the applied moments, geometrical and elastic properties of the specimen. The energy release rate contribution for each beam can be obtained using Equation (1) and summed to calculate the total energy release rate as: $J=G=J_{1}+J_{2}+J_{3}$. A detailed derivation is provided in Appendix B.

A typical loading curve ( $M_{1}$ vs. $\left.\theta_{1}\right)$ of the debonded beam is shown in Figure 7 for a CFRP/C14.8-32 core specimen with $1.4 \mathrm{~mm}$ thick face sheet. The energy-release rate, $G$, was obtained using Equation (1), and was plotted against rotation, $\theta_{1}$, of the debonded beam. As the test is controlled using the rotation of arm-1 (or the debonded arm), $\theta_{1}$, is considered in the plot. When the crack starts to propagate, the slope drops sharply and nearly approaches zero. Thus, the initiation fracture toughness, $\Gamma$, can be identified from the deviation of the slope in the $G$ vs. $\theta_{1}$ plot (see Figure 7b). This approach is qualitatively akin to finding the delamination initiation toughness in the standard DCB test (ASTM D5528) ${ }^{43}$. A MATLAB code was employed to substitute moments in Equation (1) and to identify the departure of the slope in $G$ vs. $\theta_{1}$ plot. 
The deduced initiation fracture toughness was recorded for a range of mode mixity conditions to create a map of the interface fracture toughness as a function of phase angle, $\Gamma(\psi)$.

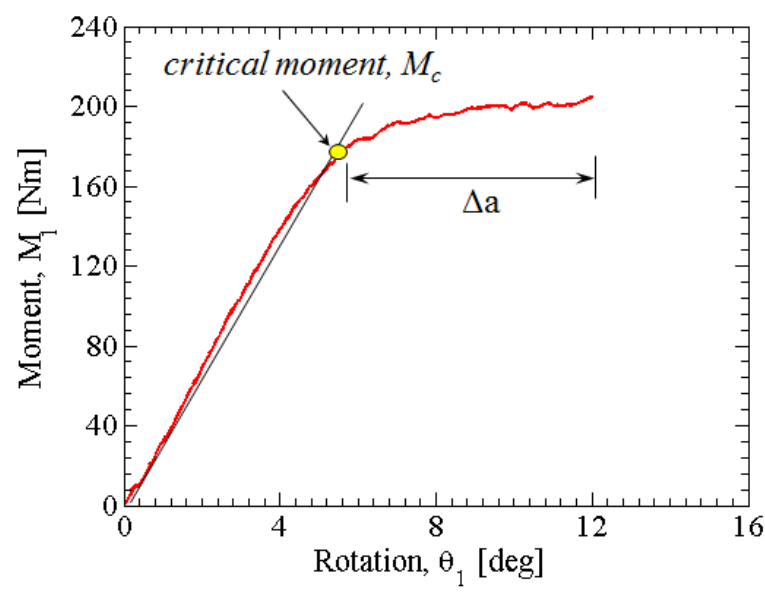

(a)

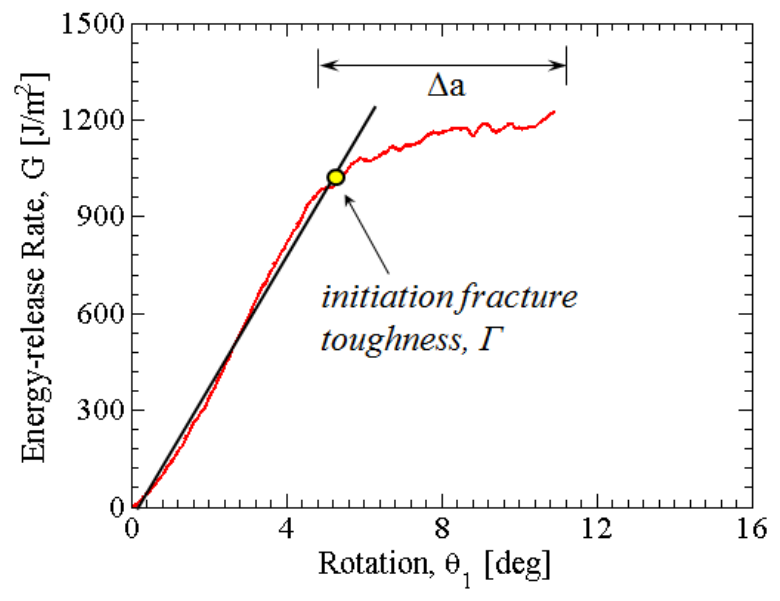

(b)

Figure 7. Typical moment and energy-release rate plots for a CFRP/C1-4.8-32 honeycomb cored specimen with $h_{f}=1.4 \mathrm{~mm}, h_{c}=40 \mathrm{~mm}$ : (a) Moment, $M_{l}$ vs. Rotation, $\theta_{l}$, and (b) Energy release rate, $G$ vs. Rotation, $\theta_{l}$ of the debonded beam.

\section{Experimental Results and Discussion}

Testing was carried out on the prepared DCB-UBM sandwich specimens and fracture toughness was calculated using the proposed data reduction scheme. The influence of various parameters on the fracture toughness such as core density, face sheet thickness, core paper material properties and crack propagation direction were studied. Prior to start of each test, the moment ratio $(M R)$ pertaining to a specific mode mixity phase angle $(\psi)$ has to be provided as input. The phase angle $(\psi)$ for each specimen type was obtained numerically (refer to Appendix A). Table 3 provides a list of $M R$ values and the corresponding phase angles for each specimen type tested. Each specimen was loaded at a constant rate of $10 \%$ min until crack propagation occurred, and was un-loaded manually. DCB-UBM fracture testing for a CFRP/C1-4.8-64 honeycomb core specimen at $M R=2\left(\psi=-35^{\circ}\right)$ is shown in Figure 8.

To collect ample amount of datasets, the test was repeated several times at a specific $M R$ on a single specimen which resulted in a crack increment of $10 \mathrm{~mm}$ for each cycle. In Table 3, $M R<$ 0 corresponds to arms opening relative to each other and $M R>0$ refers to arms rotating in the clock-wise direction (see Figures 5 and 6). In terms of the phase angle values (in degrees) a pure mode I scenario corresponds to $0^{\circ}$, whilst a pure mode II loading exist at $90^{\circ}$. Therefore, the mode I dominance can be assumed to exist within the bounds: $-10^{\circ} \leq \psi \leq 10^{\circ}$. 
Table 3. Moment ratio $(M R)$ chosen for the tested DCB-UBM honeycomb cored specimens with various core types. Phase angle $(\psi)$ is provided in parenthesis.

\begin{tabular}{|l|c|}
\hline \multicolumn{1}{|c|}{ Core Type } & Moment Ratio $(\psi[$ deg] $)$ \\
\hline \multicolumn{2}{|c|}{ W - direction } \\
\hline $\mathrm{C} 1-4.8-32\left(h_{f}=0.35 \mathrm{~mm}\right)$ & $1\left(-49^{\circ}\right), 1.5\left(-40^{\circ}\right), 2\left(-32^{\circ}\right), 3\left(-24^{\circ}\right), 5\left(-19^{\circ}\right),-20\left(-6^{\circ}\right),-10\left(-4^{\circ}\right)$ \\
\hline $\mathrm{C} 1-4.8-32\left(h_{f}=1.40 \mathrm{~mm}\right)$ & $1\left(-52^{\circ}\right), 2\left(-35^{\circ}\right), 3\left(-29^{\circ}\right), 10\left(-20^{\circ}\right),-20\left(-14^{\circ}\right),-10\left(-12^{\circ}\right),-3\left(-2^{\circ}\right)$ \\
\hline $\mathrm{C} 1-4.8-64\left(h_{f}=1.40 \mathrm{~mm}\right)$ & $1\left(-52^{\circ}\right), 2\left(-35^{\circ}\right), 3\left(-29^{\circ}\right), 10\left(-20^{\circ}\right),-20\left(-14^{\circ}\right),-3\left(-2^{\circ}\right)$ \\
\hline $\mathrm{C} 1-4.8-96\left(h_{f}=1.40 \mathrm{~mm}\right)$ & $2\left(-36^{\circ}\right), 3\left(-29^{\circ}\right),-3\left(-8^{\circ}\right),-3\left(-2^{\circ}\right)$ \\
\hline $\mathrm{CN} 1-4.8-32\left(h_{f}=1.40 \mathrm{~mm}\right)$ & $1\left(-54^{\circ}\right), 2\left(-36^{\circ}\right), 7.5\left(-21^{\circ}\right), 10\left(-18^{\circ}\right),-6\left(-6^{\circ}\right)$ \\
\hline \multicolumn{2}{|c|}{$\boldsymbol{L}^{\circ}$ direction } \\
\hline $\mathrm{C} 1-4.8-32\left(h_{f}=0.35 \mathrm{~mm}\right)$ & $1\left(-49^{\circ}\right), 2\left(-32^{\circ}\right), 5\left(-19^{\circ}\right), 15\left(-12^{\circ}\right),-20\left(-6^{\circ}\right),-10\left(-4^{\circ}\right)$ \\
\hline $\mathrm{C} 1-4.8-32\left(h_{f}=1.40 \mathrm{~mm}\right)$ & $1\left(-49^{\circ}\right), 2\left(-32^{\circ}\right), 3\left(-24^{\circ}\right), 5\left(-19^{\circ}\right),-20\left(-6^{\circ}\right),-10\left(-4^{\circ}\right),-7.5\left(-2^{\circ}\right)$ \\
\hline $\mathrm{C} 1-4.8-64\left(h_{f}=1.40 \mathrm{~mm}\right)$ & $1\left(-52^{\circ}\right), 2\left(-35^{\circ}\right), 3\left(-29^{\circ}\right), 10\left(-20^{\circ}\right),-20\left(-14^{\circ}\right),-3\left(-2^{\circ}\right)$ \\
\hline $\mathrm{C} 1-4.8-96\left(h_{f}=1.40 \mathrm{~mm}\right)$ & $2\left(-36^{\circ}\right), 5\left(-25^{\circ}\right),-20\left(-17^{\circ}\right),-5\left(-12^{\circ}\right),-3\left(-2^{\circ}\right)$ \\
\hline $\mathrm{CN} 1-4.8-32\left(h_{f}=1.40 \mathrm{~mm}\right)$ & $1\left(-54^{\circ}\right), 2\left(-36^{\circ}\right), 7.5\left(-21^{\circ}\right), 10\left(-18^{\circ}\right),-20\left(-12^{\circ}\right),-6\left(-6^{\circ}\right)$ \\
\hline
\end{tabular}

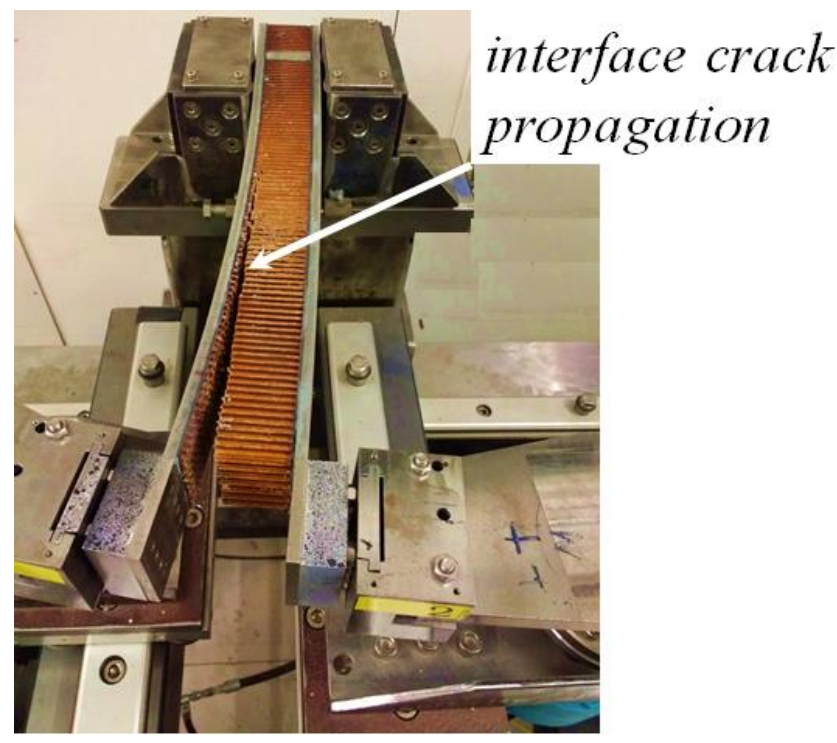

Figure 8. Face/core interface crack propagation at $M R=2\left(\psi=-35^{\circ}\right)$ for CFRP/C1-4.8-64 honeycomb core specimen (L-direction) with $h_{f}=1.4 \mathrm{~mm}, h_{c}=40 \mathrm{~mm}$. 


\section{Effect of honeycomb core density on fracture toughness, $\Gamma$}

To study the influence of the honeycomb core density on the interface fracture toughness, three core densities (32, 64 and $\left.96 \mathrm{~kg} / \mathrm{m}^{3}\right)$ of the Cormaster $\mathrm{C} 1$ type core were examined. The cores were composed of Nomex ${ }^{\circledR}$ T412 paper material with face sheet and core thickness, $h_{f}=1.4$ $\mathrm{mm}$ and $h_{c}=40 \mathrm{~mm}$, respectively. Fracture toughness measurements were carried out at several mode mixity conditions (refer to Table 3 ) and is shown as a function of phase angle $(\psi)$ in Figure 9. The experimental interface toughness data was fitted with the general expression provided by Hutchinson and Suo ${ }^{17}$ :

$$
\Gamma(\psi)=G_{1 c}\left(1+\tan ^{2}[(1-\Lambda) \psi]\right)
$$

where $G_{l c}$ is the mode I interface toughness, $\Gamma\left(\psi=0^{\circ}\right)$, and $\Lambda$ is a dimensionless constant. The interface fracture toughness in Figure 9 was fitted (by eye) using Equation (2) and the measured mode I fracture toughness, $G_{l c}$. The curve fitting dimensionless constant, $\Lambda$ are provided in each plot. Testing were performed in both $\mathrm{L}$ and $\mathrm{W}$ directions, commonly referred to as the ribbon and transverse directions, respectively. It is observed that the fracture toughness, $\Gamma$, in Wdirection was consistently higher than the L-direction for all the density classes studied here (see Figure 9). This is due to cell wall alignment (see Figure 4) with respect to crack propagation. When the crack advances in the $\mathrm{W}$-direction, there are more cell wall material compared to the ribbon direction. In addition, at a constant mode mixity phase angle $(\psi)$ and a given crack propagation direction, the fracture toughness, $\Gamma$, was seen to increase with rise in core density. Furthermore and as expected, the fracture toughness increases with increase in phase angle $(\psi)$. Thus, at higher values of $\psi$ higher moment values are required to initiate crack propagation.

For a given mode mixity phase angle $(\psi)$ and crack propagation direction, specimens with the $96 \mathrm{~kg} / \mathrm{m}^{3}$ dense core exhibited the highest interface fracture toughness while the lowest toughness was obtained for the specimen with $32 \mathrm{~kg} / \mathrm{m}^{3}$ dense core. At increased mode mixity scenarios in the negative phase angle regime, higher moment magnitudes are required for crack propagation. For specimens with $96 \mathrm{~kg} / \mathrm{m}^{3}$ dense honeycomb core, fracture testing was carried out only until a mixed-mode regime of $\psi=-32^{\circ}$. The magnitude of moments needed to propagate a crack in predominant mode II conditions are higher. The carriage plates supporting the actuators were designed to carry a load up to $275 \mathrm{Nm}$. Hence, for the denser core cases testing were limited until the mixed-mode regime. Whereas for other core types, testing was carried out at predominant mode I, mixed-mode I/II and predominant mode II conditions. 


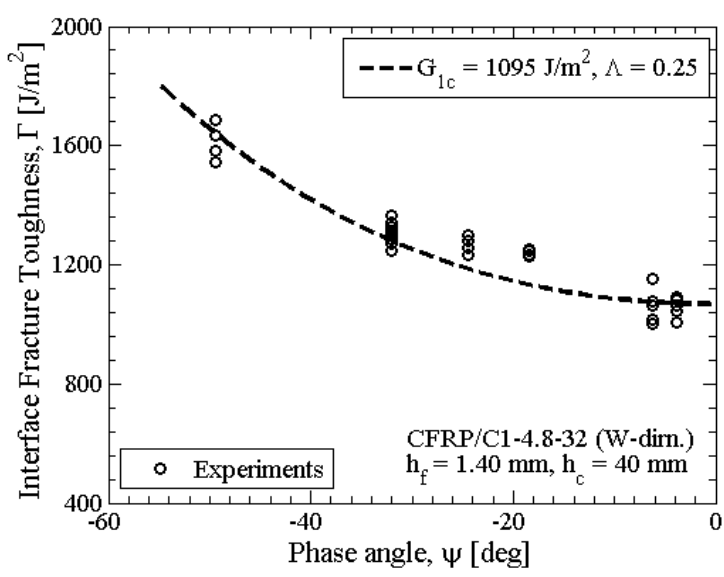

(a)

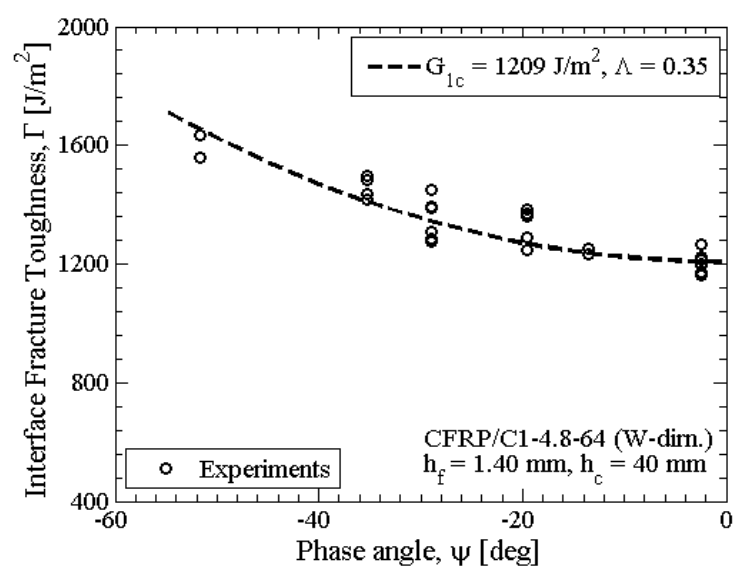

(c)

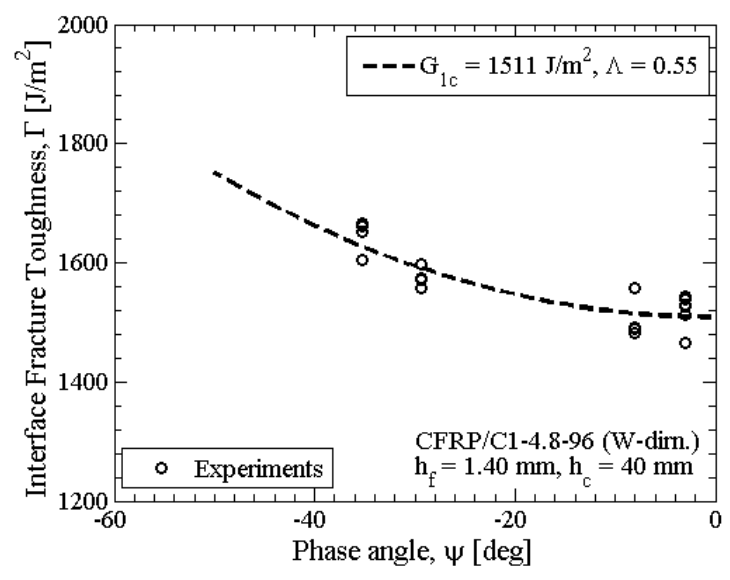

(e)

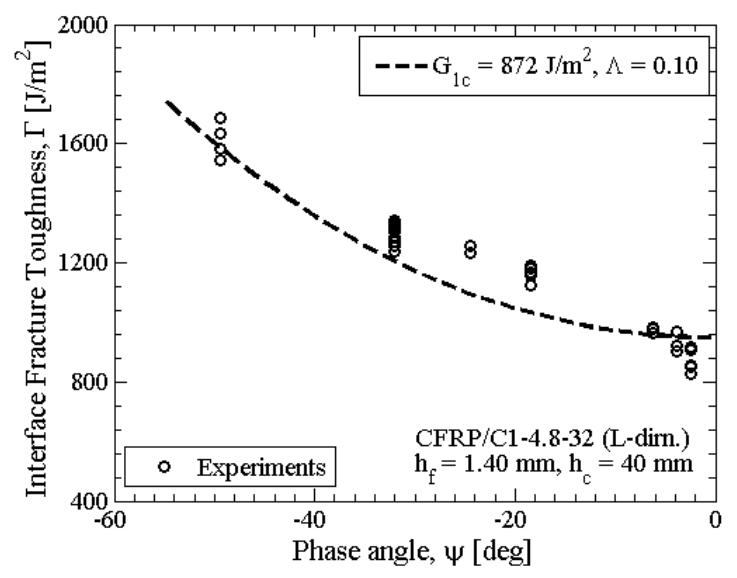

(b)

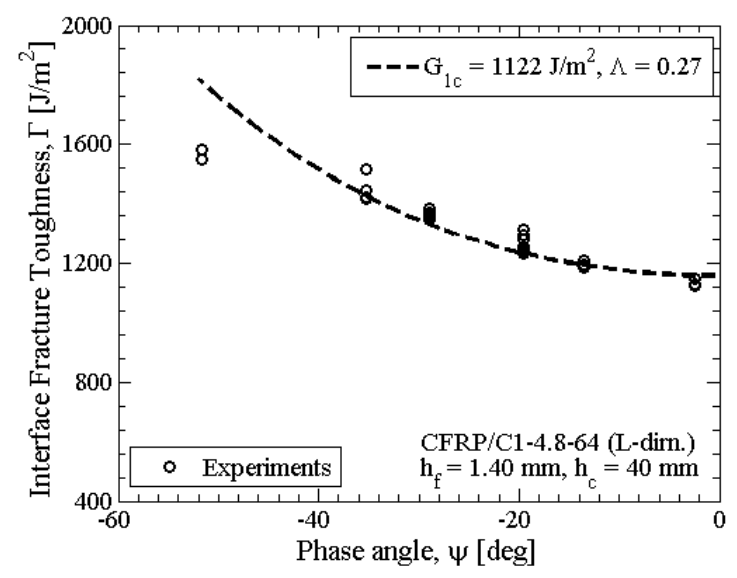

(d)

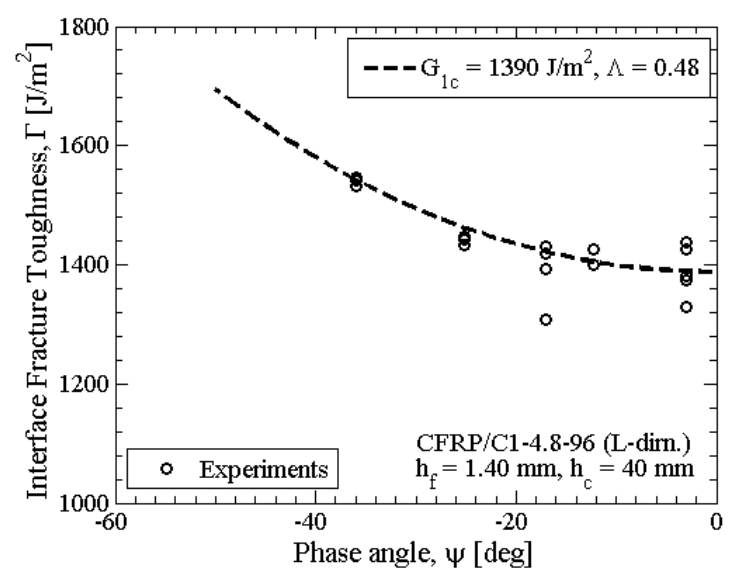

(f)

Figure 9. Interface fracture toughness as a function of mode mixity phase angle $(\psi)$ for CFRP/C1 type honeycomb core sandwich specimens with densities: (a) $32 \mathrm{~kg} / \mathrm{m}^{3}$ (W-direction), (b) $32 \mathrm{~kg} / \mathrm{m}^{3}$ (L-direction), (c) $64 \mathrm{~kg} / \mathrm{m}^{3}$ (W-direction), (d) $64 \mathrm{~kg} / \mathrm{m}^{3}$ (L-direction), (e) $96 \mathrm{~kg} / \mathrm{m}^{3}$ (W-direction), and (f) $96 \mathrm{~kg} / \mathrm{m}^{3}$ (L-direction). 
The crack path in a honeycomb sandwich face/core interface is highly non-uniform. For most of the tested cases, crack propagation was observed to occur at the face/core interface just beneath the meniscus layer. The toughness data shown in Figure 9 shows scatter which may be attributed to the crack propagation through resin rich cells. A schematic illustration of this typical behavior is provided in Figure 10b. During the sandwich panel manufacturing process, the epoxy adhesive layer is amassed at the face/core interface creating a local resin profile in the cells ${ }^{44}$, which affects the crack advancement path. It was observed that when the crack encounters the meniscus layer, it dives back into the core, and climbs back again to the interface to continue further advancement. Figure 10(a) shows such a behavior of crack switching between interfacecore-interface to avoid resin rich cells in a C1-4.8-32 honeycomb core specimen. This was further confirmed upon inspection of fracture surfaces after testing, see Figure 10(c).

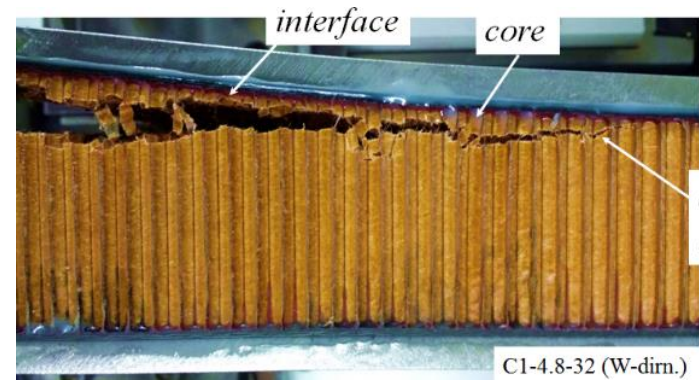

(a)

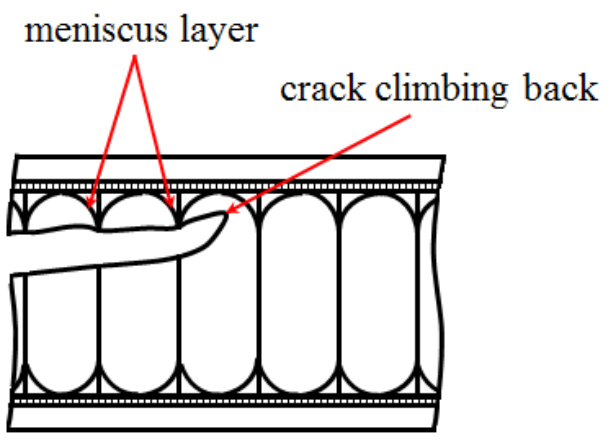

(b)

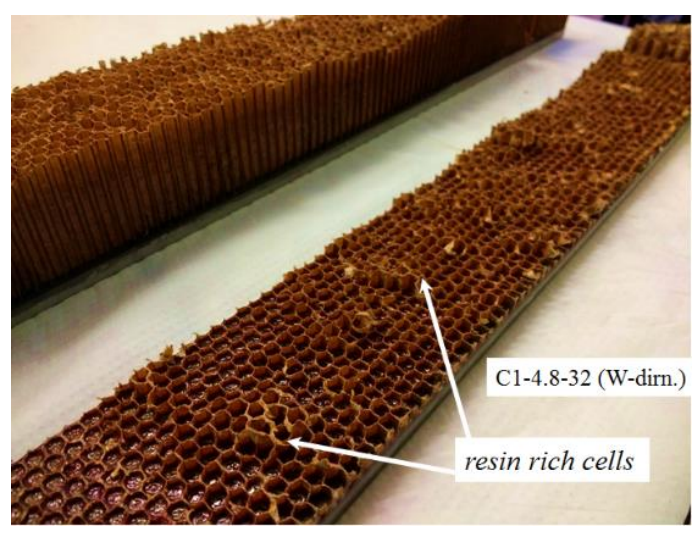

(c)

Figure 10. CFRP/C1-4.8-32 honeycomb core specimen, $h_{f}=1.4 \mathrm{~mm}, h_{c}=40 \mathrm{~mm}$ : (a) crack propagation through interface-core-interface regions at $M R=5\left(\psi=-19^{\circ}\right)$, (b) schematic illustration of crack advancement just beneath the meniscus layer, and (c) fracture surface with resin rich pockets. 


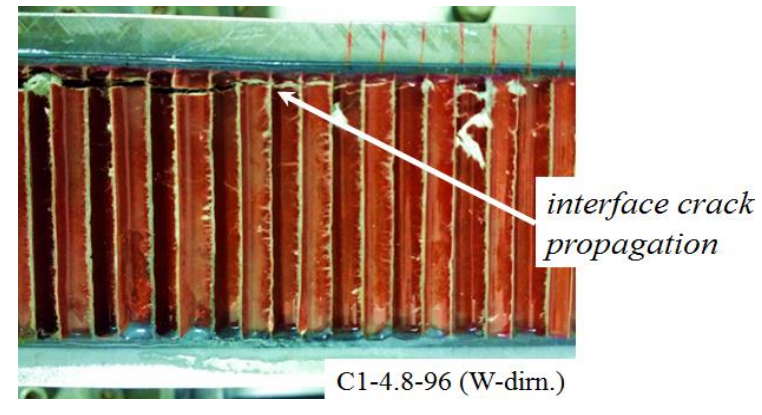

(a)

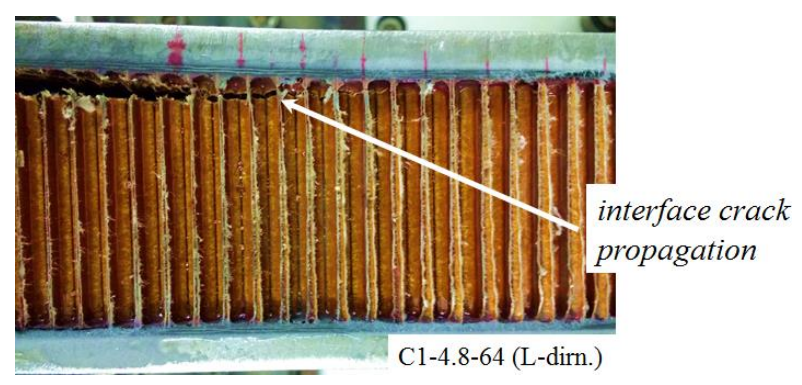

(b)

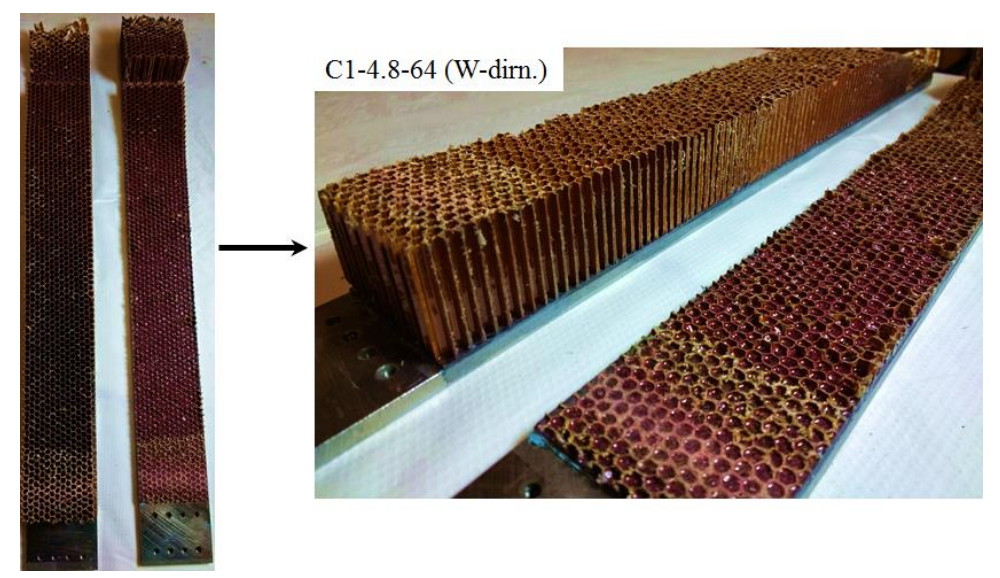

(c)

Figure 11. Face/core interface crack propagation for: (a) CFRP/C1-4.8-96 (W-direction) core specimen at $M R=-5\left(\psi=-12^{\circ}\right)$, (b) CFRP/C1-4.8-64 (L-direction) core specimen at $M R=10$ $\left(\psi=-20^{\circ}\right)$, and $(\mathrm{c})$ fracture surface of $\mathrm{C} 1-4.8-64(\mathrm{~W}$-direction).

Figures 11 (a) and (b) show the crack propagation paths in DCB-UBM specimens with 64 and $96 \mathrm{~kg} / \mathrm{m}^{3}$ dense honeycomb cores. Figure 11(c) shows fracture surfaces for a specimen with C14.8-64 type core. The fracture surfaces showed similar characteristics as that of the $32 \mathrm{~kg} / \mathrm{m}^{3}$ cored specimens. As with previous case, the crack propagated just beneath the meniscus layers (see Figures 11(a) and (b)).

A comparison of the mode I fracture toughness of specimens with three core densities, namely 32,64 and $96 \mathrm{~kg} / \mathrm{m}^{3}$ of the Cormaster C1 core type was undertaken. In terms of the phase angle, $\psi$, pure mode I conditions can be assumed to exist in the range, $-10^{\circ} \leq \psi \leq 10^{\circ}$. Fracture toughness obtained from mode I dominant tests for both L- and $\mathrm{W}$ - directions were compared across core densities, and are provided in Figure 12. It must be noted that the face sheet and core thickness were constant across all core densities at, $h_{f}=1.4 \mathrm{~mm}$ and $h_{c}=40 \mathrm{~mm}$ respectively. Moreover, all the core types considered in this section were made from Nomex ${ }^{\circledR}$ T412 paper sheets. A highest mode I fracture toughness of $1511 \mathrm{~J} / \mathrm{m}^{2}$ was measured for the $96 \mathrm{~kg} / \mathrm{m}^{3} \mathrm{dense}$ core in the W direction, and a lowest value of $872 \mathrm{~J} / \mathrm{m}^{2}$ was obtained for the $32 \mathrm{~kg} / \mathrm{m}^{3}$ core type 
in the $\mathrm{L}$ direction. The $96 \mathrm{~kg} / \mathrm{m}^{3}$ dense core specimens exhibited highest coefficient of variation, $\mathrm{CV}$, in both $\mathrm{L}$ and $\mathrm{W}$ directions (see Figure 12).

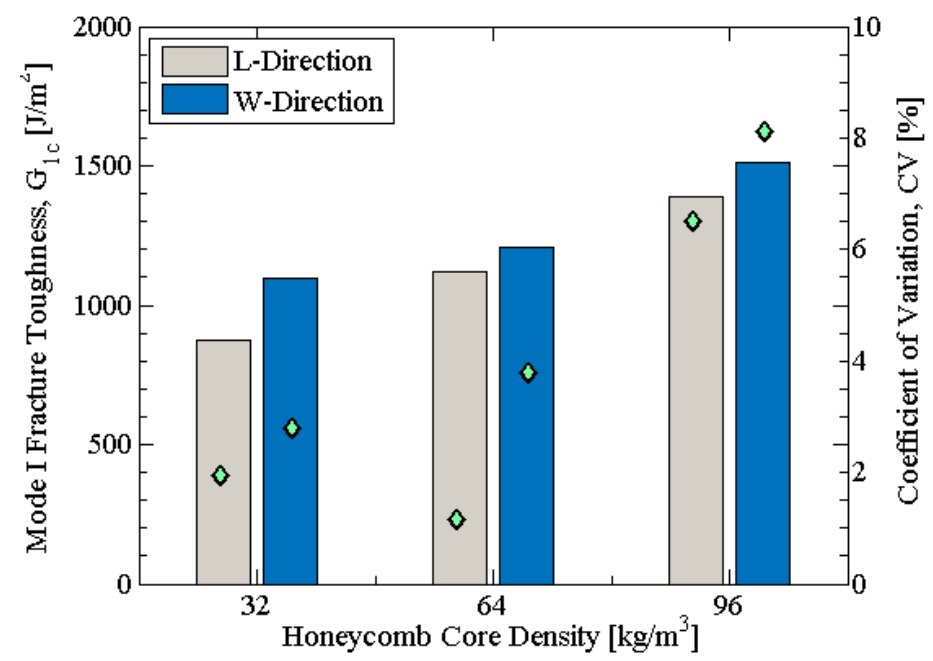

Figure 12. Mode I fracture toughness and coefficient of variation, $\mathrm{CV}$, in $\mathrm{L}$ and $\mathrm{W}$ crack propagation directions for CFRP/C1 type core with various densities; $h_{f}=1.4 \mathrm{~mm}, h_{c}=40 \mathrm{~mm}$.

\section{Effect of face sheet thickness on fracture toughness, $\Gamma$}

Fracture characterization of CFRP/C1-4.8-32 honeycomb core specimens with a thinner face sheet, $h_{f}=0.35 \mathrm{~mm}$ was performed and compared with interface toughness values obtained for specimens with the thicker face sheet, $h_{f}=1.4 \mathrm{~mm}$. Testing was carried out in both $\mathrm{W}$ and $\mathrm{L}$ directions for the thin face sheet CFRP/C1-4.8-32 cored specimens at several mode mixity phase angle $(\psi)$ values. Equation (2) was employed to plot the fracture toughness as a function of phase angle, and is provided in Figure 13. The curve fitting was performed by eye and the dimensionless constant, $\Lambda$, along with mode I interface toughness, $G_{l c}$, are provided in the plot. Refer to Table 3 for the tested moment ratio $(M R)$, and the corresponding phase angle $(\psi)$ for specimens in both crack propagation directions ( $\mathrm{L}$ and $\mathrm{W}$ ). Similar to previous tests scatter in the data was observed.

Similar to specimens with thicker face sheets, the interface fracture toughness in the $\mathrm{W}$ direction is higher compared to the L direction. The toughness ranged from 1500 to $2400 \mathrm{~J} / \mathrm{m}^{2}$ for the W direction and from 1200 to $2300 \mathrm{~J} / \mathrm{m}^{2}$ for the $\mathrm{L}$ direction case. The fracture toughness values are higher compared to the specimens with thicker face sheets. A comparison was also made against mode I fracture toughness, $G_{l c}$, of specimens with thicker face sheet and same core density, see Figure 14. A toughness value of $1510 \mathrm{~J} / \mathrm{m}^{2}$ in the $\mathrm{W}$ direction, and $1240 \mathrm{~J} / \mathrm{m}^{2}$ in the L direction were recorded. Coefficient of variation, $\mathrm{CV}$ was observed to be higher for specimens with the 
thinner face sheets in both crack propagation directions. A highest $\mathrm{CV}$ of $4 \%$ was obtained for the thinner face sheet specimens in the L crack propagation direction.

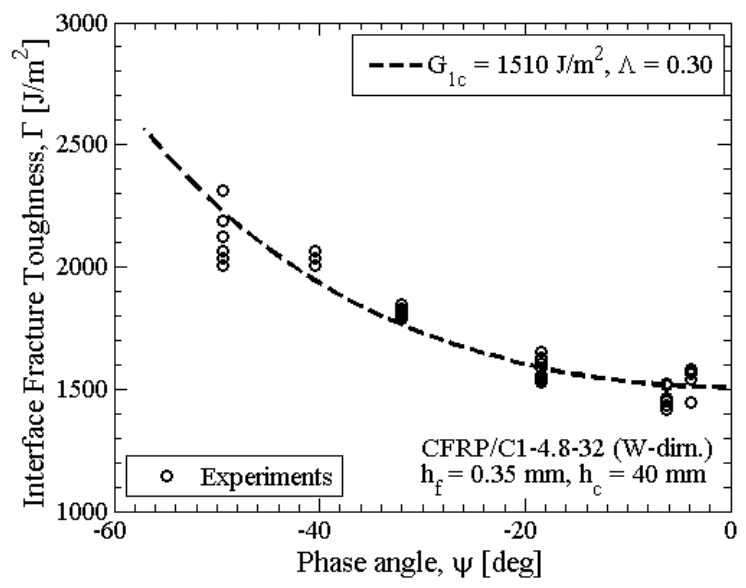

(a)

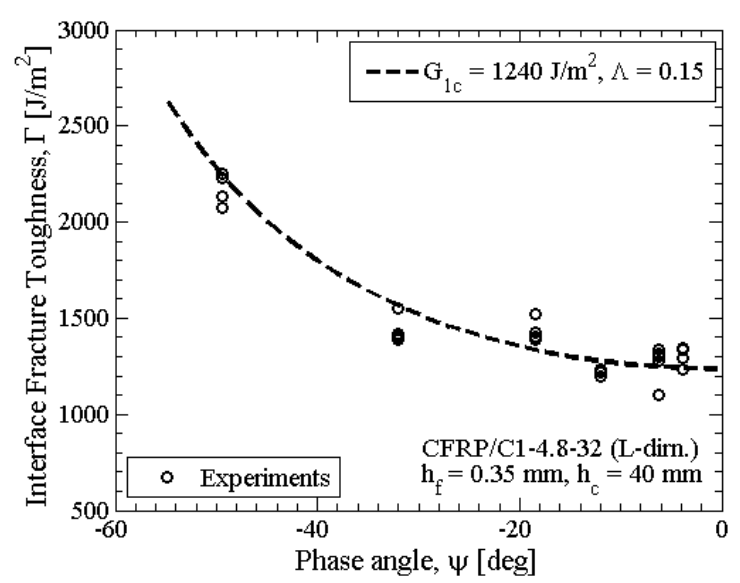

(b)

Figure 13. Fracture toughness $(\Gamma)$ vs. phase angle $(\psi)$ for a CFRP/C1-4.8-32 honeycomb core sandwich specimen with $h_{f}=0.35 \mathrm{~mm}$ and $h_{c}=40 \mathrm{~mm}$ : (a) W direction, (b) L direction.

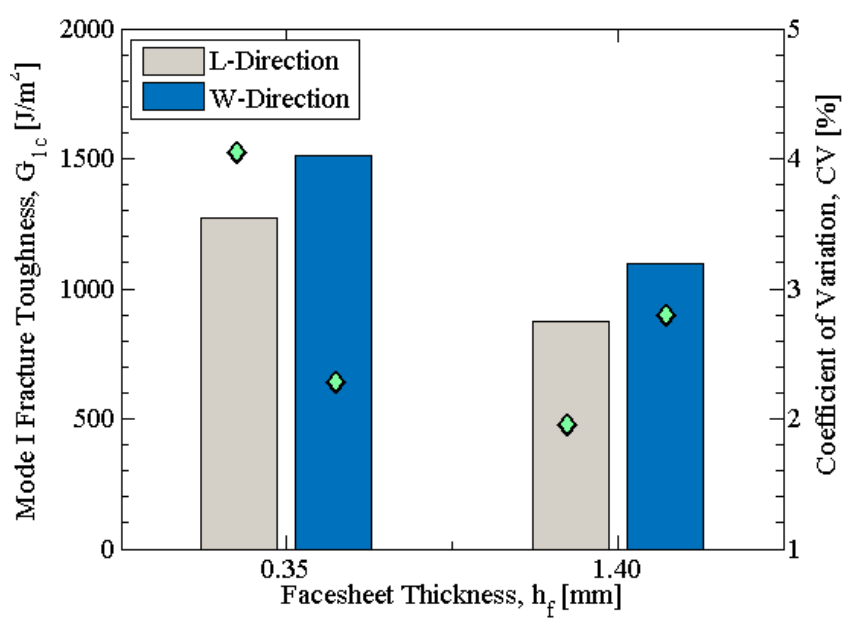

Figure 14. Mode I fracture toughness and coefficient of variation, $\mathrm{CV}$, in $\mathrm{L}$ and $\mathrm{W}$ crack propagation directions for CFRP/C1-4.8-32 honeycomb core specimens; $h_{c}=40 \mathrm{~mm}$ and $h_{f}=$ 0.35 and $1.4 \mathrm{~mm}$.

Figure 15(a) shows a typical crack propagation path for CFRP/C1-4.8-32 honeycomb cored specimens with face sheets of $h_{f}=0.35 \mathrm{~mm}$. Interface crack propagation was observed at all phase angles and the crack surface region is shown in Figure 15(b). It was also observed that the epoxy adhesive had trickled down into the cells during sandwich panel fabrication creating a 
localized resin rich pocket as shown in Figure 15(c). The crack path shifted into the core, away from the face/core interface to circumvent this localized zone and climbed back to the surface to resume propagation along the interface. This behavior was similar to what was observed in specimens with thicker face sheets $\left(h_{f}=1.4 \mathrm{~mm}\right)$. The higher fracture toughness for specimens with thinner face sheets may be attributed to the crack propagation occurring very close to the face sheet through the meniscus layer (see Figure 16(a)). In the case of specimens with thicker face sheets, the crack propagates well beneath the meniscus layer leaving more core residue, see Figure 16(b).

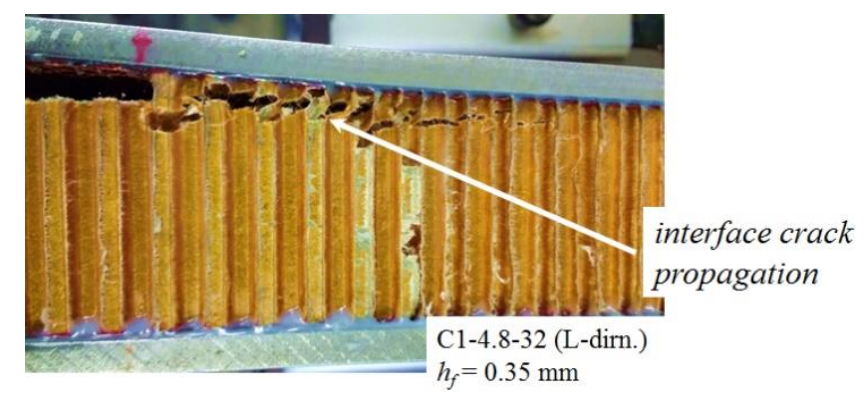

(a)

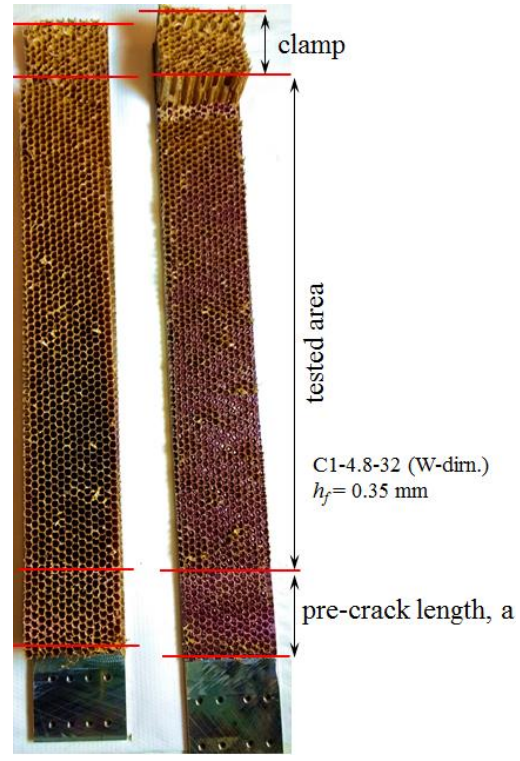

(b)

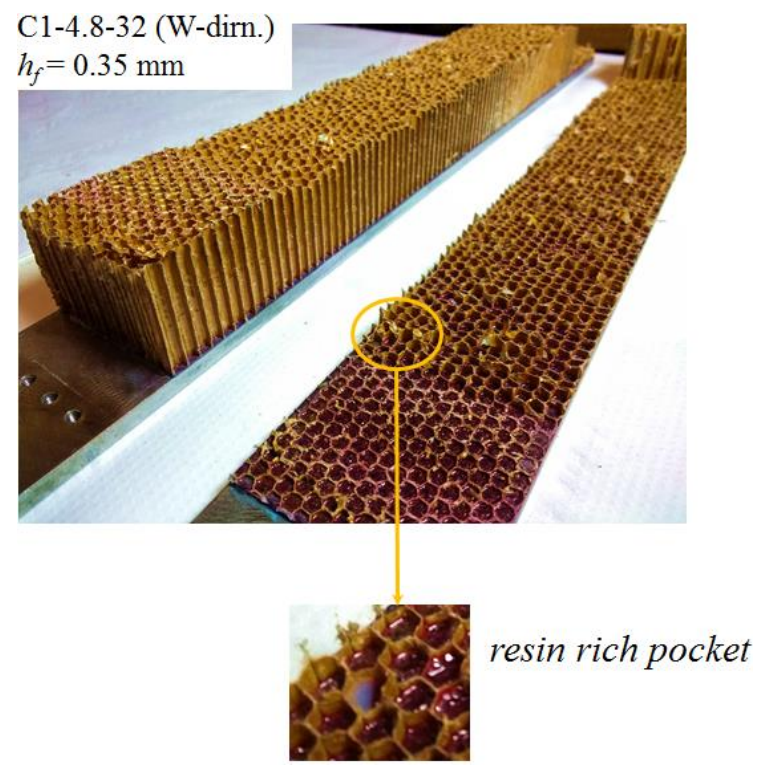

(c)

Figure 15. (a) Face/core interface crack propagation path in a CFRP/C1-4.8-32 core specimen, $h_{f}=0.35 \mathrm{~mm}, h_{c}=40 \mathrm{~mm}$, (b) fracture surface showing interface crack propagation throughout (W-direction), and (c) resin rich pocket observed in cells. 
C1-4.8-32 (W-dirn.), $h_{f}=0.35 \mathrm{~mm}$
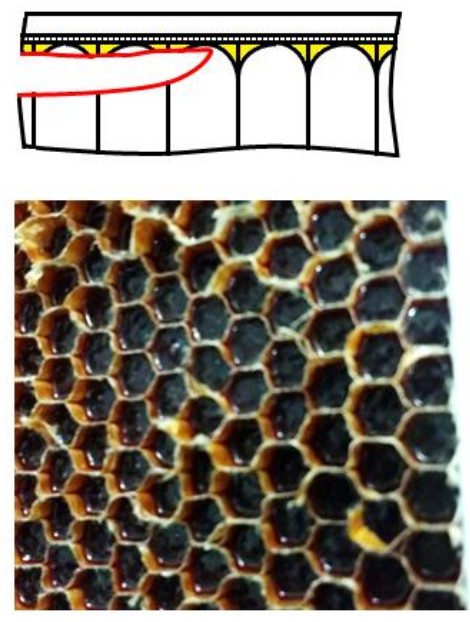

(a)
C1-4.8-32 (W-dirn.), $h_{f}=1.40 \mathrm{~mm}$
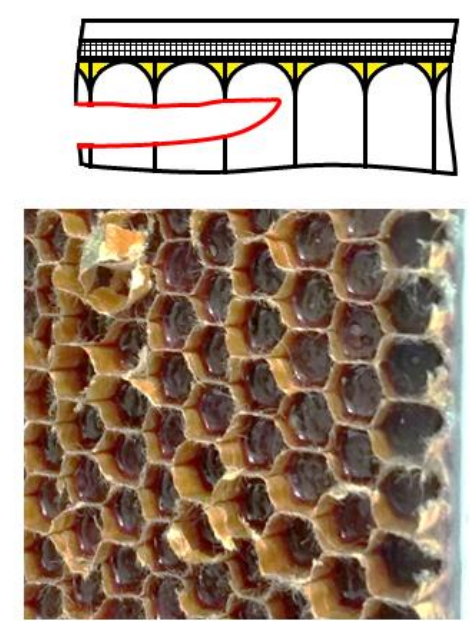

(b)

Figure 16. Crack propagation paths in specimens with thin and thick face sheets (a) schematic illustration of crack propagation close to face sheet (above) and fracture surface revealing short meniscus layer residue (below), and (b) schematic illustration of crack propagation beneath the meniscus layer in specimen with thick face sheet (above) and fracture surface with more core residue (below).

\section{Effect of honeycomb paper material on fracture toughness, $\Gamma$}

In the previous sections, the investigated specimens consisted of Cormaster $\mathrm{C} 1$ type cores which were composed of Nomex ${ }^{\circledR}$ T412 paper. The effect of core paper material on the interface fracture toughness is presented in this section and a $32 \mathrm{~kg} / \mathrm{m}^{3}$ dense core with a Cormaster N636 core type comprising of Kevlar N636 paper material was utilized. The study was conducted in both $\mathrm{W}$ and $\mathrm{L}$ crack propagation directions with, $h_{f}=1.40 \mathrm{~mm}$ and $h_{c}=40 \mathrm{~mm}$. As previous, the interface fracture toughness was expressed as a function of phase angle ( $\psi$ ) using Equation (2) and are shown in Figure 17. The fracture toughness measured in the $\mathrm{W}$ direction was found to be higher than $\mathrm{L}$ direction, akin to previous measurements involving the Cormaster $\mathrm{C} 1$ type core. 


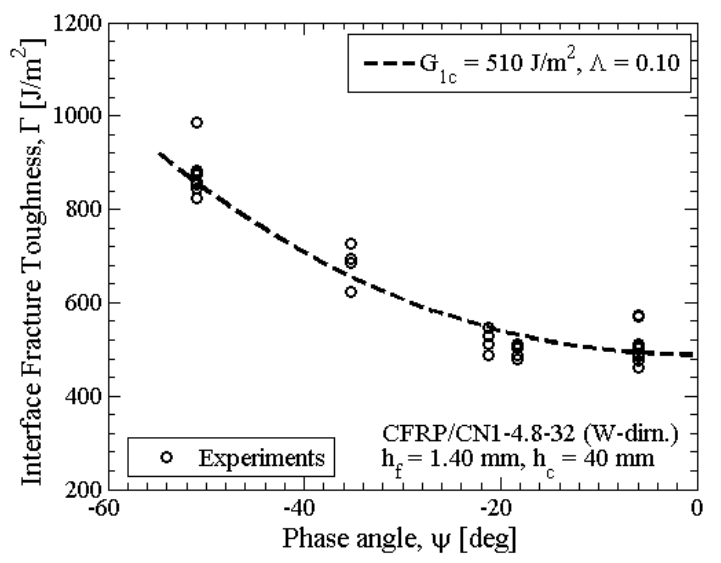

(a)

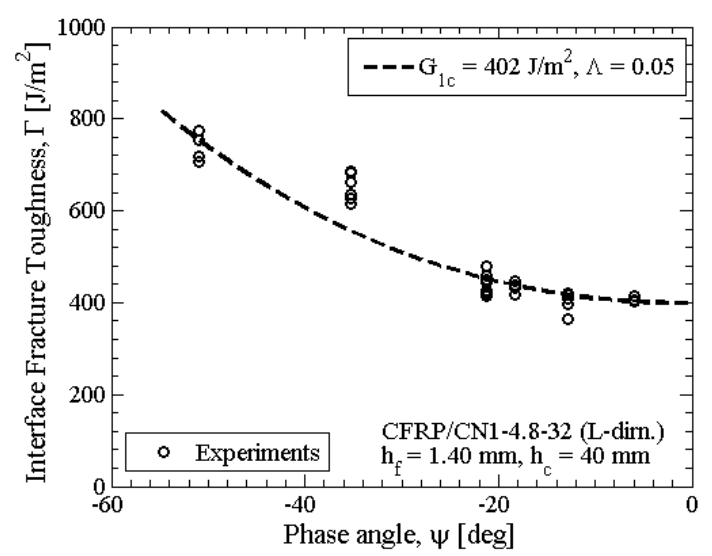

(b)

Figure 17. Interface fracture toughness $(\Gamma)$ vs. phase angle $(\psi)$ for a CFRP/CN1-4.8-32 honeycomb core sandwich specimen with $h_{f}=0.35 \mathrm{~mm}$ and $h_{c}=40 \mathrm{~mm}$, for crack propagation in: (a) W direction, and (b) L direction.

Comparison of the mode I fracture toughness, $G_{l c}$, for specimens with C1-4.8-32 and CN1-4.832 core types is presented in Figure 18. The Cormaster C1 core type exhibited higher toughness values when compared with core with Kevlar N636 paper. For the CN1-4.8-32 core type, a mode I fracture toughness of $510 \mathrm{~J} / \mathrm{m}^{2}$ and $402 \mathrm{~J} / \mathrm{m}^{2}$ were obtained in $\mathrm{W}$ and $\mathrm{L}$ directions, respectively. The coefficient of variation, $\mathrm{CV}$, is also provided in Figure 18 for both crack propagation directions. A highest $\mathrm{CV}$ of $5.8 \%$ was found for the N636 core type in $\mathrm{W}$ direction.

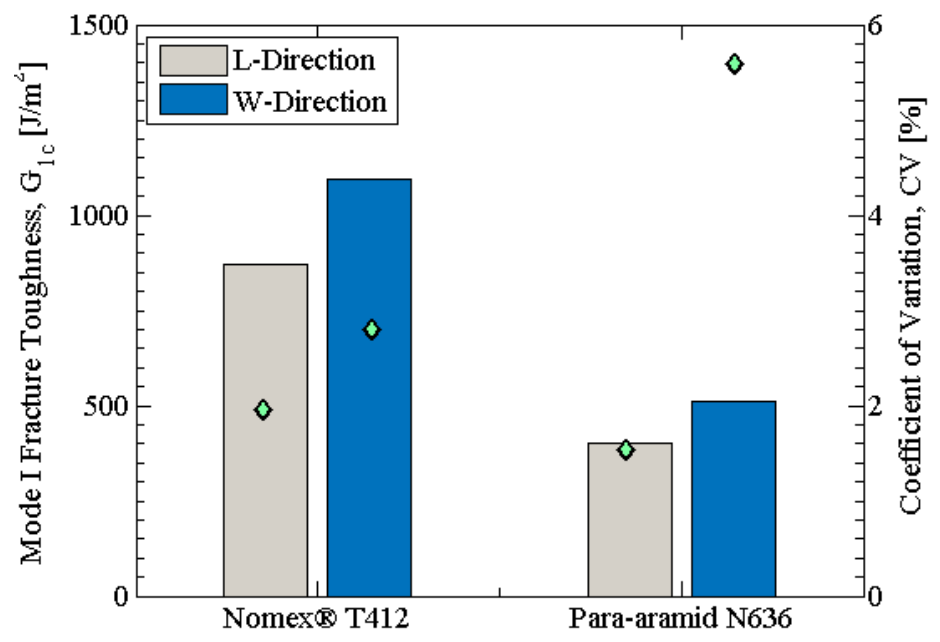

Figure 18. Comparison of mode I fracture toughness and coefficient of variation, CV, in L and W crack propagation directions for CFRP/C1-4.8-32 and CFRP/CN1-4.8-32 honeycomb core specimens; $h_{c}=40 \mathrm{~mm}$ and $h_{f}=1.4 \mathrm{~mm}$. 
Similar to specimens tested with Cormaster $\mathrm{C} 1$ cores, interface crack propagation just beneath the meniscus layer was observed at all tested mode mixity conditions. The moment ratios $(M R)$ and the corresponding phase angles at which tests were carried out for both $\mathrm{L}$ and $\mathrm{W}$ directions are provided in Table 3. Figure 19(a) shows interface crack propagation for the CFRP/N636 honeycomb core specimen. A higher amount of core residue was observed on fracture surfaces, see Figure 19(b). This may be attributed to the inherent difference in nature of the core paper material.

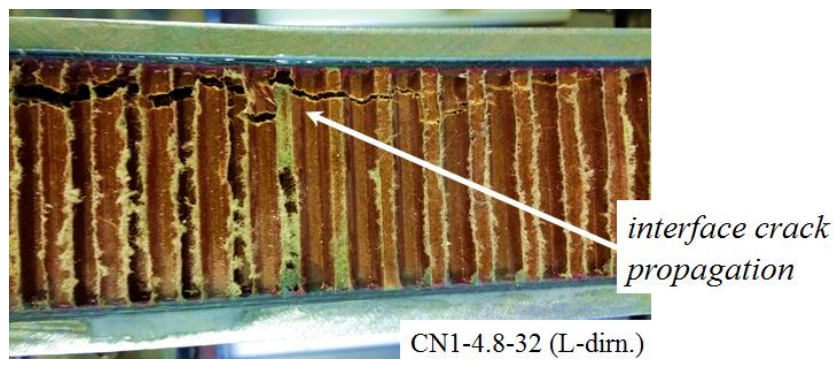

(a)

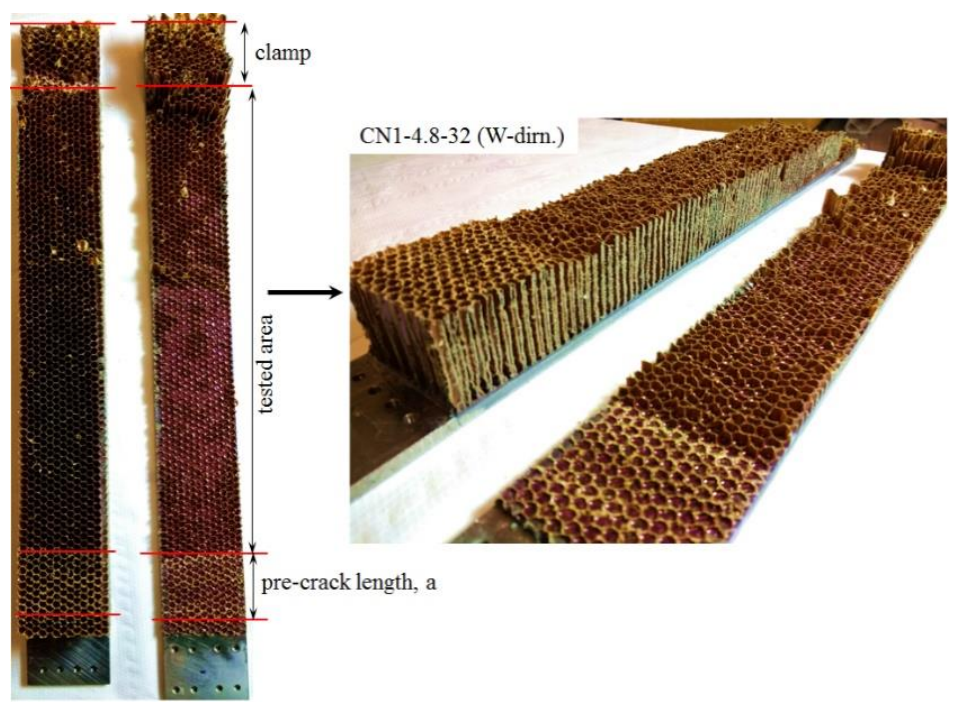

(b)

Figure 19. (a) Crack propagation path, and (b) fracture surface for CFRP/CN1-4.8-32 cored specimen; $h_{f}=1.40 \mathrm{~mm}, h_{c}=40 \mathrm{~mm}$. 


\section{Conclusions}

Fracture testing of honeycomb cored sandwich specimens were performed using the DCB-UBM test method. Two core types Cormaster C1 and Cormaster N636 were employed. The Cormaster C1 type specimens consisting of Nomex ${ }^{\circledR}$ T412 paper showed higher fracture toughness compared to specimens with N636 core comprising of Kevlar N636 paper. This was expected as Kevlar based cores were less stiff compared to the Nomex ${ }^{\circledR}$ based cores. Moreover, with increase in core density, the Nomex ${ }^{\circledR}$ based cores become stiffer. Therefore, as expected the measured fracture toughness increased with rise in core density. It was also observed that for a given core material, specimens with thinner face sheets exhibited higher fracture toughness due to a shift in crack propagation in the meniscus layer. For all the specimens, the interface fracture toughness measured in the $\mathrm{W}$ direction was higher than the $\mathrm{L}$ direction (ribbon direction). For the same face sheet properties, specimens with $96 \mathrm{~kg} / \mathrm{m}^{3}$ dense Cormaster $\mathrm{C} 1$ honeycomb core yielded the highest interface fracture toughness. The DCB-UBM test methodology with the unique way of applying pure moments directly on the crack flanks was shown to be a very robust and efficient test method for mixed mode fracture characterization of typical honeycomb core sandwich systems utilized in the aerospace industry.

\section{Appendix A: Mapping of Moment Ratio (MR) vs. Mode mixity Phase Angle ( $\psi)$}

The moment ratio, $M R$, corresponding to the desired mode mixity at which the test is carried out, must be provided as input prior to each test. The mode mixity expressed using the phase angle, $\psi$, was estimated using a 2D plane strain finite element (FE) model built in ANSYS® ${ }^{45}$, in conjunction with the Crack Surface Displacement Extrapolation (CSDE) method ${ }^{41}$. The FEmodel consisted of 4-noded linear (PLANE182) and 8-noded parabolic (PLANE183) elements with a smallest element edge length of $2.5 \mu \mathrm{m}$, see Figure 20. The 4-noded linear elements were used near the crack tip zone to utilize CSDE mode mixity method. Moments were applied on master nodes located at the neutral axis of the debonded and substrate beams (refer to Figure 6). The CSDE mixed-mode partitioning method utilizes relative crack flank displacements $\left(\delta_{x}\right.$ and $\delta_{y}$ ) to compute the phase angle, $\psi$. The mode mixity phase angle can be expressed in terms of relative crack tip displacements in the following form:

$$
\psi=\tan ^{-1}\left(\frac{\delta_{x}}{\delta_{y}}\right)
$$

The phase angle provided in Equation (3) is referred to as the reduced formulation, where the near-tip oscillations have been discounted ${ }^{41,17}$. The CSDE method is very effective in calculating mode mixity phase angles $(\psi)$ and especially when large crack tip distortions are present, which is typically the case for sandwich composites due to the high elastic mismatch across the interface ${ }^{46}$. The CSDE was implemented as a separate subroutine in ANSYS®, which was used to extract relative crack flank displacements. 
FE-analysis was performed to create a map of moment ratio, $M R$ vs. phase angle, $\psi$, for the various CFRP/honeycomb cored sandwich configurations studied in this paper. A large range of moment ratios were explored to vary the mode mixity. It should be noted that in addition to the numerical method, the phase angle, $\psi$, can also be obtained using closed form expressions for a moment loaded DCB sandwich specimen ${ }^{20,21}$. The mechanical properties of face sheet and core materials are provided in Tables 1 and 2, respectively. The total length of the DCB-UBM specimen was $500 \mathrm{~mm}$ and the pre-crack length was chosen to be $200 \mathrm{~mm}$ for all analyses. In all simulations, the magnitude of moments, $M_{1}$ and $M_{2}$ were selected such that, an energy release rate $G \approx 100 \mathrm{~J} / \mathrm{m}^{2}$ was achieved. Expensive computations are required for discrete cell modeling of honeycomb cores, and therefore it is preferred to replace the core with a homogenous continuum. Several engineering investigations show close correlation with numerical solutions and analytical equations for various honeycomb core homogenization approaches 36,37,47,48. Therefore, in the current study the honeycomb core was modeled as a continuum (as illustrated in Figure 20) using the approach originally proposed by Gibson and Ashby ${ }^{36}$, which was further expanded by Malek and Gibson ${ }^{37}$.

The sign of $M R$ is dependent on the sign of the applied moments, $M_{1}$ and $M_{2}$. There are three possible ways of rotating the crack flanks: a) $M_{1}$ and $M_{2}$ rotate clock-wise $(\mathrm{CW})$, b) $M_{1}$ and $M_{2}$ open relative to each other (Open) or c) $M_{1}$ and $M_{2}$ rotate counter-clock wise (CCW) with respect to the plane of paper. The rotation of the beam in counter clock-wise direction was taken as positive which yielded $M R>0$ for the cases when both beams rotate in CW and CCW directions. The case in which crack flanks open relative to each other will yield a negative moment ratio, $M R<0$.

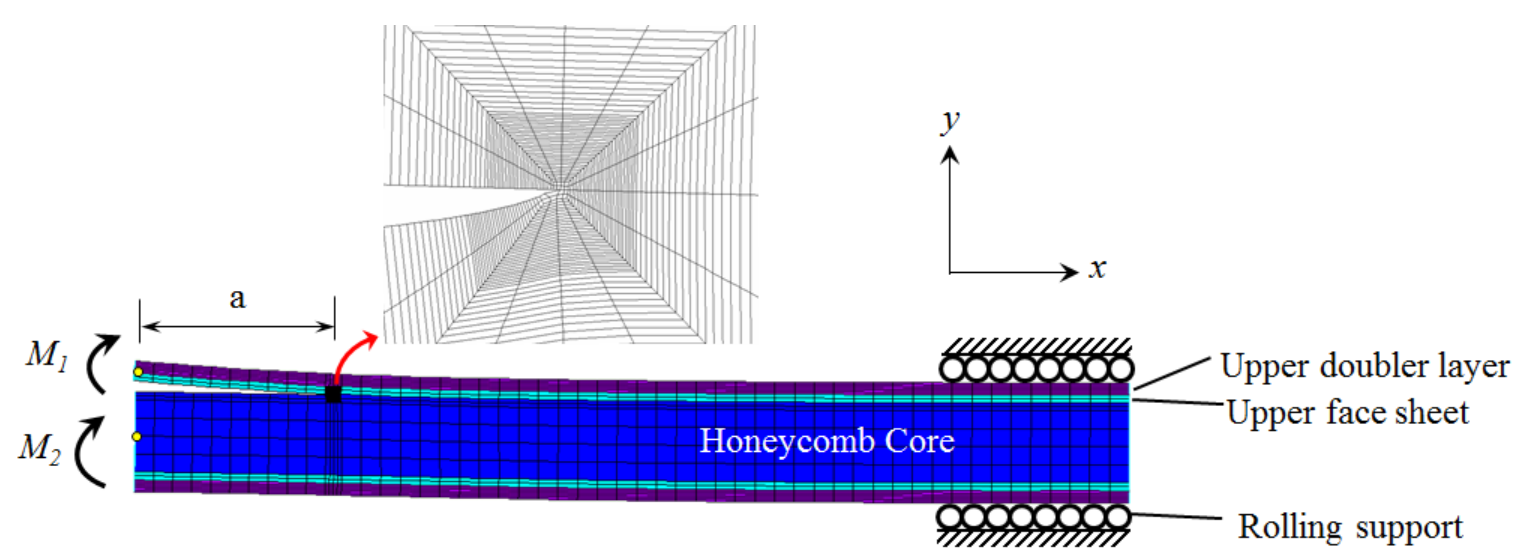

Figure 20. 2D FE-model of the reinforced DCB-UBM sandwich specimen with moments applied on the crack flanks containing high dense mesh in the near tip zone. 
Plot of moment ratio, $M R$, vs. mode mixity phase angle, $\psi$, for the CFRP/Cormaster C1 honeycomb core configurations with the three core density classes 32,64 and $96 \mathrm{~kg} / \mathrm{m}^{3}$ are provided in Figure 21. For $M R>1$ in the $\mathrm{CCW}$ direction, it was observed in the FE-model that the crack flanks collided with each other. Hence, the phase angle values for the CCW case are provided only in the range for $0 \leq M R \leq 1$ for all three core types in Figure 21 .

The influence of core thickness, on phase angle is clearly evident from the Figures 21 (a) - (c). For a constant $M R$, a thinner core results in a higher phase angle values in the negative scale for $M R$ in the ranges $-20<M R<-1$ and $1<M R<20$. However, the difference in phase angle is small in the range $-1<M R<1$ for the two core thicknesses considered here. For testing, the $M R$ values were picked to target three mode mixity regions: 1$)$ mode I $\left(-10^{\circ} \leq \psi \leq 10^{\circ}\right)$, mixedmode $\left(-45^{\circ} \leq \psi \leq-10^{\circ}\right)$ and mode II dominant $\left(\psi \leq-45^{\circ}\right)$. The $M R$ values and the corresponding phase angle $(\psi)$ for each specimen are enlisted in Table 3. It should be noted that a negative phase angle $(\psi)$ indicates that the crack has propensity to kink into the face sheet. In general, face sheets are tougher and hence the crack will continue to grow hugging the interface. A positive $\psi$ will tend to drive the crack into the core. Therefore it is desired that the fracture testing is carried out at $M R$ corresponding to a negative $\psi$. All the $M R$ values selected in this paper for various sandwich configurations pertained to a negative $\psi$. Similarly, $M R$ vs. $\psi$ maps for the CFRP/C1-4.8-32 core configuration with $h_{f}=0.35 \mathrm{~mm}$ and for the CFRP/CN1-4.8-32 configuration are provided in Figures 22 and 23. 


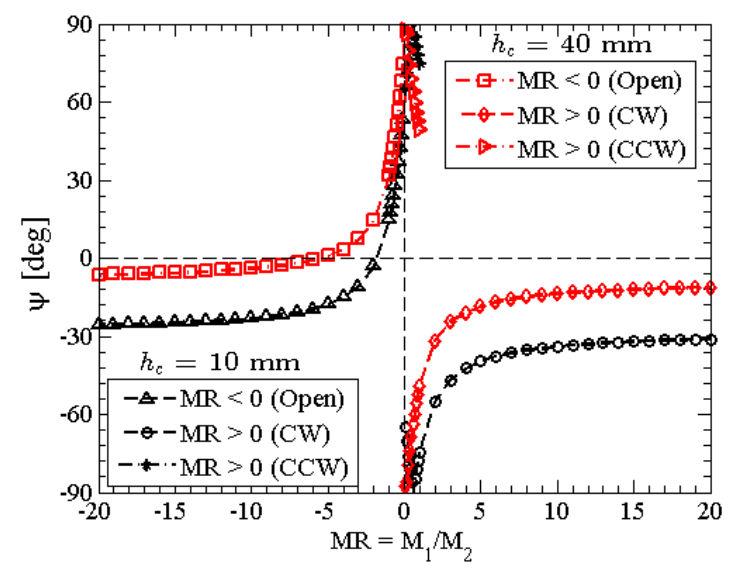

(a)

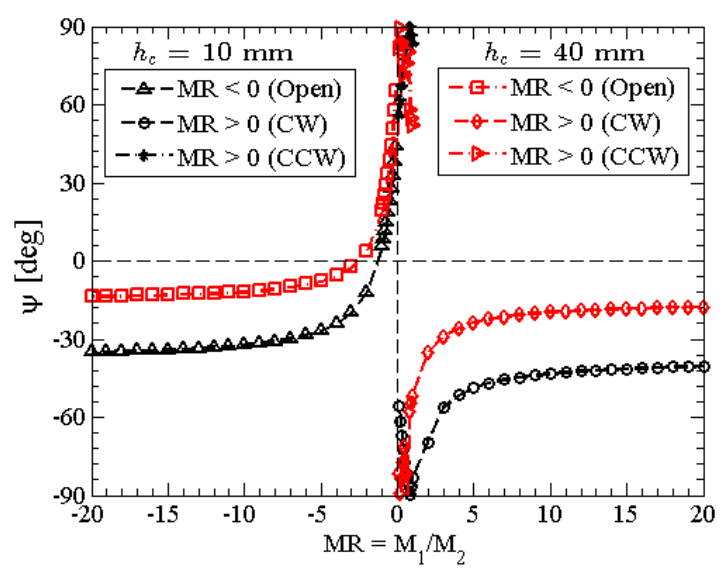

(b)

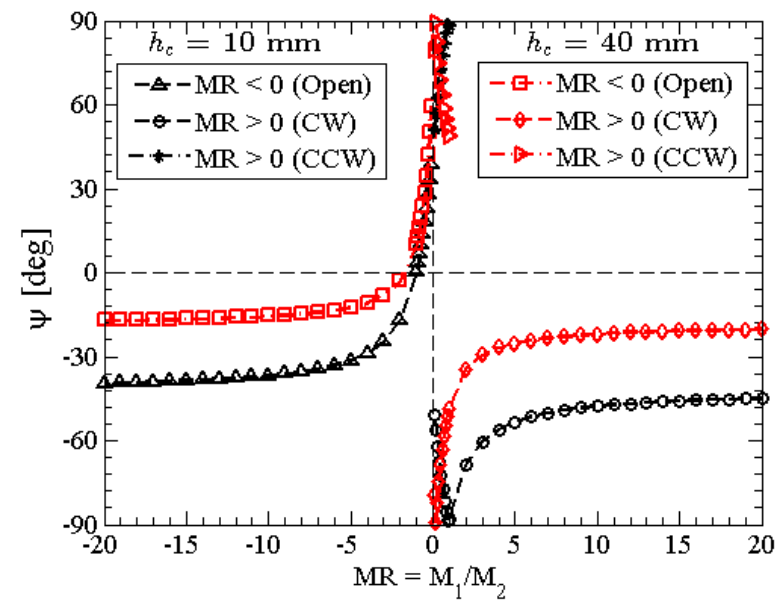

(c)

Figure 21. Plot of moment ratio, $M R$, vs. phase angle, $\psi$, for the CFRP/Cormaster $\mathrm{C} 1$ honeycomb core specimen configurations with: (a) 32, (b) 64, and (c) $96 \mathrm{~kg} / \mathrm{m}^{3}$ density class and with a face sheet thickness, $h_{f}=1.4 \mathrm{~mm}$. 


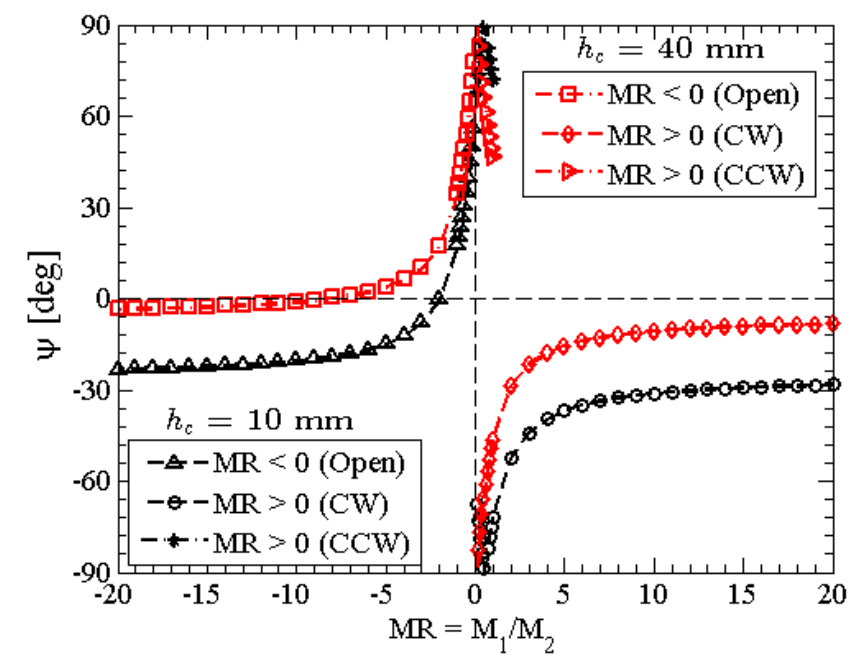

Figure 22. Moment ratio $(M R)$, vs. phase angle $(\psi)$, for $32 \mathrm{~kg} / \mathrm{m}^{3}$ dense honeycomb core specimen configuration with $h_{f}=0.35 \mathrm{~mm}$.

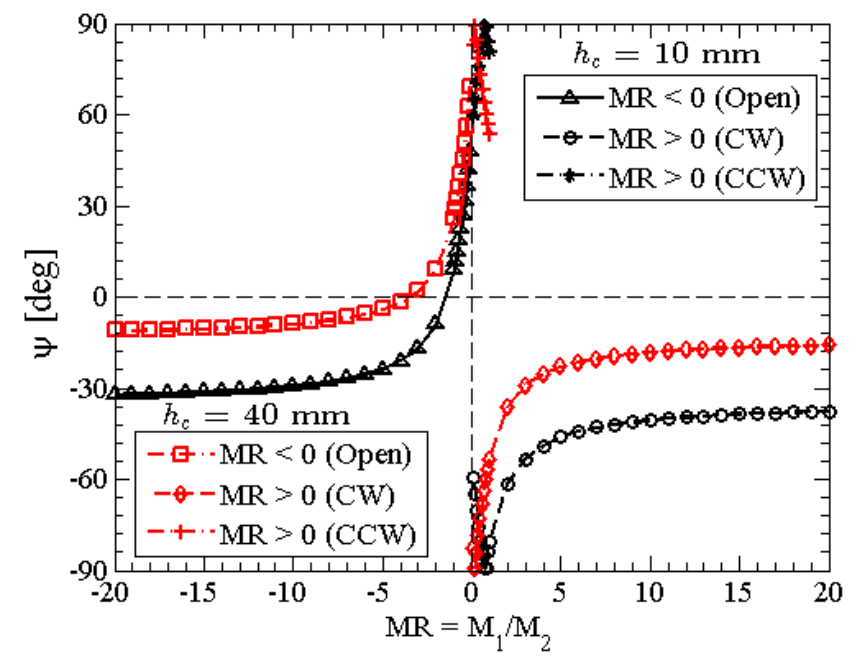

Figure 23. Moment ratio $(M R)$, vs. phase angle $(\psi)$, for CFRP/N636 core specimen configuration (CN1-4.8-32) with $h_{f}=1.40 \mathrm{~mm}$. 


\section{Appendix B: Energy release rate of reinforced DCB-UBM specimen}

The energy release rate of a multi-layer DCB sandwich specimen subjected to moments can be computed using the $J$-integral expression provided in Equation (1) ${ }^{19}$. The $J$-integral expression is simplified and re-expressed for the reinforced DCB-UBM specimen. Beam \#1 comprises of the upper face sheet $\left(h_{f}\right)$ and doubler layer $\left(h_{r}\right)$ until the pre-crack length, a. The $J$-integral evaluated for beam $\# 1, J_{l}$, is given as:

$$
\begin{aligned}
J_{1}= & \frac{\bar{E}_{r} M_{1}^{2}}{6\left(A_{1} D_{1}-B_{1}^{2}\right)^{2}}\left[-A_{1}^{2} \frac{h_{r}}{4}\left(h_{f}^{2}+3 h_{r}^{2}\right)+3 A_{1} B_{1}\left(h_{f} h_{r}\right)-3 B_{1}^{2}\left(h_{f}\right)\right]+ \\
& \frac{\bar{E}_{f} M_{1}^{2}}{6\left(A_{1} D_{1}-B_{1}^{2}\right)^{2}}\left[-A_{1}^{2} \frac{h_{f}}{4}\left(h_{f}^{2}+3 h_{r}^{2}\right)+3 A_{1} B_{1}\left(h_{f} h_{r}\right)-3 B_{1}^{2}\left(h_{f}\right)\right]
\end{aligned}
$$

where $A_{1}=\bar{E}_{f} h_{f}+\bar{E}_{r} h_{r}, \quad B_{1}=\frac{h_{f} h_{r}}{2}\left(\bar{E}_{f}-\bar{E}_{r}\right)$ and $D_{1}=\frac{\bar{E}_{r} h_{r}}{4}\left(h_{f}^{2}+\frac{h_{r}^{2}}{3}\right)+\frac{\bar{E}_{f} h_{f}}{4}\left(h_{r}^{2}+\frac{h_{f}^{2}}{3}\right)$. For plane stress condition, $\bar{E}=E$, and for plane strain condition, and $\bar{E}=E /\left(1-v^{2}\right)$. Similarly, for beam \#2, the $J$-integral is of the form:

$$
\begin{aligned}
J_{2}= & \frac{\bar{E}_{c} M_{2}^{2}}{6\left(A_{2} D_{2}-B_{2}^{2}\right)^{2}}\left[-A_{2}^{2} \frac{h_{c}}{4}\left(h_{c}^{2}+3\left(h_{f}+h_{r}\right)^{2}\right)-3 A_{2} B_{2} h_{c}\left(h_{f}+h_{r}\right)-3 B_{2}^{2}\left(h_{c}\right)\right]+ \\
& \frac{\bar{E}_{f} M_{2}^{2}}{6\left(A_{2} D_{2}-B_{2}^{2}\right)^{2}}\left[-A_{2}^{2} \frac{3 h_{f}}{4}\left(h_{c}^{2}-2 h_{r} h_{c}+\frac{1}{3} h_{f}^{2}+h_{r}^{2}\right)-3 A_{2} B_{2} h_{f}\left(h_{r}-h_{c}\right)-3 B_{2}^{2}\left(h_{f}\right)\right]+ \\
& \frac{\bar{E}_{r} M_{2}^{2}}{6\left(A_{2} D_{2}-B_{2}^{2}\right)^{2}}\left[-A_{2}^{2} \frac{3 h_{r}}{4}\left(h_{c}^{2}+2 h_{f} h_{c}+\frac{1}{3} h_{r}^{2}+h_{f}^{2}\right)+3 A_{2} B_{2} h_{r}\left(h_{f}+h_{c}\right)-3 B_{2}^{2}\left(h_{r}\right)\right]
\end{aligned}
$$

where $A_{2}=\bar{E}_{c} h_{c}+\bar{E}_{f} h_{f}+\bar{E}_{r} h_{r}, B_{2}=\frac{\bar{E}_{f} h_{f}}{2}\left(h_{c}-h_{r}\right)+\frac{\bar{E}_{r} h_{r}}{2}\left(h_{c}+h_{f}\right)-\frac{\bar{E}_{c} h_{c}}{2}\left(h_{f}+h_{r}\right)$ and

$$
D_{2}=\bar{E}_{c} h_{c}\left(\frac{h_{c}^{2}}{12}+\frac{h_{f}^{2}}{4}+\frac{h_{f} h_{r}}{2}+\frac{h_{r}^{2}}{4}\right)+\bar{E}_{f} h_{f}\left(\frac{h_{c}^{2}}{4}+\frac{h_{f}^{2}}{12}-\frac{h_{c} h_{r}}{2}+\frac{h_{r}^{2}}{4}\right)+\bar{E}_{r} h_{r}\left(\frac{h_{c}^{2}}{4}+\frac{h_{f}^{2}}{4}+\frac{h_{c} h_{f}}{2}+\frac{h_{r}^{2}}{12}\right) .
$$

The $J$-integral for beam \#3 can be expressed as:

$$
\begin{aligned}
J_{3}= & \frac{\bar{E}_{c} M_{3}^{2}}{6 D_{3}^{2}}\left[\frac{h_{c}^{3}}{4}\right]-\frac{\bar{E}_{f} M_{3}^{2}}{3 D_{3}^{2}}\left[\frac{h_{f}}{4}\left(3 h_{c}^{2}+6 h_{c} h_{f}+4 h_{f}^{2}\right)\right]- \\
& \frac{\bar{E}_{r} M_{3}^{2}}{3 D_{3}^{2}}\left[\frac{3 h_{r}}{4}\left(\left(2 h_{c}+4 h_{f}\right) h_{r}+\frac{4}{3} h_{r}^{2}+\left(h_{c}+2 h_{f}\right)^{2}\right)\right]
\end{aligned}
$$


where $D_{3}=2 \bar{E}_{r} h_{f} h_{r}\left(h_{f}+h_{r}+h_{c}\right)+\bar{E}_{r} h_{r}\left(\frac{2}{4} h_{r}^{2}+h_{c} h_{r}+\frac{h_{c}^{2}}{2}\right)$.

\section{Acknowledgements}

The financial support from the European Aviation Safety Agency (EASA) and the Danish Centre for Composite Structures and Materials (DCCSM) funded by the Danish Council for Strategic Research within Sustainable Energy and Environment (Grant: 09-067212) are gratefully acknowledged. Furthermore, the support from AIRBUS with supply of honeycomb core specimens is highly appreciated. EASA program manager, Dr. Simon Waite and Mr. Ralf Hilgers, AIRBUS Operations $\mathrm{GmbH}$, showed keen interest in this project and are gratefully acknowledged.

\section{References}

1. Transportation Safety Board of Canada. Loss of Rudder in Flight. Minister of Public Works and Government Services, Canada, 2007.

2. Glaessgen EH, Reeder JR, Sleight DW, et al. Debonding Failure of Sandwich-Composite Cryogenic Fuel Tank with Internal Core Pressure. J Spacecr Rockets 2005; 42: 613-627.

3. Prasad S, Carlsson LA. Debonding and crack kinking in foam core sandwich beams-I. Analysis of fracture specimens. Eng Fract Mech 1994; 47: 813-824.

4. Prasad S, Carlsson LA. Debonding and crack kinking in foam core sandwich beams-II. Experimental investigation. Eng Fract Mech 1994; 47: 825-841.

5. Li X, Carlsson LA. The Tilted Sandwich Debond (TSD) Specimen for Face/Core Interface Fracture Characterization. J Sandw Struct Mater 1999; 1: 60-75.

6. Berggreen C, Carlsson LA. A Modified TSD Specimen for Fracture Toughness Characterization - Fracture Mechanics Analysis and Design. J Compos Mater 2010; 44: 1893-1912.

7. Berggreen C, Quispitupa A, Costache A, et al. Face/core mixed mode debond fracture toughness characterization using the modified TSD test method. J Compos Mater 2014; 48: 1939-1945.

8. Fields RE, Zarda R. Analysis and Test Methodology for Fracture Mechanics of Unbonded Sandwich Structures. Martin Maerietta Stud Task Report, EDF No MMO TKR 10722739-001 1994.

9. Cantwell WJ, Davies P. A test technique for assessing core-skin adhesion in composite 
sandwich structures. J Mater Sci Lett 1994; 13: 203-205.

10. Carlsson LA. On the Design of the Cracked Sandwich Beam (CSB) Specimen. J Reinf Plast Compos 1991; 10: 434-444.

11. Zenkert D. Poly(vinyl chloride) sandwich core materials: Fracture behaviour under mode II loading and mixed-mode conditions. Mater Sci Eng A 1989; 108: 233-240.

12. Quispitupa A, Berggreen C, Carlsson LA. On the analysis of a mixed mode bending sandwich specimen for debond fracture characterization. Eng Fract Mech 2009; 76: 594613.

13. Quispitupa A, Berggreen C, Carlsson LA. Design Analysis of the Mixed Mode Bending Sandwich Specimen. J Sandw Struct Mater 2010; 12: 253-272.

14. Ratcliffe J, Krueger R. Face Sheet/Core Disbonding in Sandwich Composite Components: A Road Map to Standardization: Test Method Development. In: 11th International Conference on Sandwich Structures. Dania Beach, Florida, 2016.

15. Ratcliffe JG, Reeder JR. Sizing a single cantilever beam specimen for characterizing facesheet-core debonding in sandwich structure. J Compos Mater 2011; 45: 2669-2684.

16. Quispitupa A, Berggreen C, Carlsson LA. Face/core interface fracture characterization of mixed mode bending sandwich specimens. Fatigue Fract Eng Mater Struct 2011; 34: 839-853.

17. Hutchinson JW, Suo Z. Mixed Mode Cracking in Layered Materials. Adv Appl Mech 1991; 29: 63-191.

18. Sørensen BF, Jørgensen K, Jacobsen TK, et al. DCB-specimen loaded with uneven bending moments. Int J Fract 2006; 141: 163-176.

19. Lundsgaard-Larsen C, Sørensen BF, Berggreen C, et al. A modified DCB sandwich specimen for measuring mixed-mode cohesive laws. Eng Fract Mech 2008; 75: 2514 2530 .

20. Kardomateas GA, Berggreen C, Carlsson L a. Energy-Release Rate and Mode Mixity of Face/Core Debonds in Sandwich Beams. AIAA J 2013; 51: 885-892.

21. Saseendran V, Berggreen C, Carlsson LA. Fracture Mechanics Analysis of Reinforced DCB Sandwich Debond Specimen Loaded by Moments. AIAA J 2017; 56: 413-422.

22. Reeder JR, Demarco K, Whitley KS. The use of doubler reinforcement in delamination toughness testing. Compos Part A Appl Sci Manuf 2004; 35: 1337-1344.

23. Grau DL, Qiu XS, Sankar B V. Relation between Interfacial Fracture Toughness and Mode-mixity in Honeycomb Core Sandwich Composites. J Sandw Struct Mater 2006; 8: 187-203.

24. Rinker M, Ratcliffe JG, Adams DO, et al. Characterizing Facesheet/Core Disbonding in 
Honeycomb Core Sandwich Structure. NASA/CR-2013-217959 NIA Rep No 2013-0115 2013.

25. Schütz GmbH \& Co. Cormaster C1 Technical Data. Selters, Germany, 2016.

26. Schütz GmbH \& Co. Cormaster N636 Preliminary technical data. Selters, Germany, 2016.

27. Hexcel Corporation. HexPly ® $913125^{\circ} \mathrm{C}$ curing epoxy matrix. Stamford, CT, 2016.

28. Woo K, Whitcomb JD. Effects of fiber tow misalignment on the engineering properties of plain weave textile composites. Compos Struct 1997; 37: 343-355.

29. 3M Aerospace and Aircraft Maintenance Department. Scotch-Weld TM Structural Adhesive Film AF 163-2 Technical Datasheet. 2009.

30. UDDEHOLM. Uddeholm Impax ® Supreme. Udeeholm, 2014.

31. 3M. Scotch-Weld ${ }^{T M}$ Epoxy Adhesives DP460 Off-White and DP460NS. St. Paul, MN, 2017.

32. ASTM-D3039/D3039M-08. Standard Test Method for Tensile Properties of Polymer Matrix Composite Materials. 2014.

33. ASTM-D7078/7078M-12. Standard Test Method for Shear Properties of Composite Materials by V-Notched Rail Shear Method. 2012.

34. Schäuble R, Goldstein M, Petersilge M. Elastic properties of the CFRP Facesheets in Honeycomb core Sandwich Panels (DoSS/TFSanDis). Internal report IMWS V554/2017, Halle, 2017.

35. Schäuble R, Goldstein M, Petersilge M. SCB Fracture Toughness Tests on Honeycomb Sandwich Material - Technical Report. Internal report IMWS V793/2017, Halle, 2017.

36. Gibson LJ, Ashby MF. Cellular Solids: Structure and Properties. Cambridge University Press, 1999.

37. Malek S, Gibson L. Effective elastic properties of periodic hexagonal honeycombs. Mech Mater 2015; 91: 226-240.

38. Hähnel F, Bugiel A, Wolf K. Determination of macroscopic properties of different aramid paper based honeycomb cores. Technische Universität Dresden, Chair of Aircraft Engineering, Internal report ILR/LFT-IR17-19, Dresden, 2017.

39. Berggreen C, Saseendran V, Carlsson LA. A Modified DCB-UBM Test Method for Interfacial Fracture Toughness Characterization of Sandwich Composites. (Manuscript in preperation) 2017.

40. MTS Systems Corporation. FlexTest ${ }^{T M}$ SE Digital Servo Test Controller. Eden Prairie, 2010. 
41. Berggreen C, Simonsen BC, Borum KK. Experimental and Numerical Study of Interface Crack Propagation in Foam-cored Sandwich Beams. J Compos Mater 2007; 41: 493-520.

42. Rice JR. A Path Independent Integral and the Approximate Analysis of Strain Concentration by Notches and Cracks. J Appl Mech 1968; 35: 379.

43. ASTM International. ASTM D5528-13 Standard Test Method for Mode I Interlaminar Fracture Toughness of Unidirectional Fiber-Reinforced Polymer Matrix Composites. 2013.

44. Giglio M, Manes A, Gilioli A. Investigations on sandwich core properties through an experimental-numerical approach. Compos Part B Eng 2012; 42: 361-374.

45. ANSYS Inc. ANSYS® Mechanical User's Guide. Canonsburg, PA, 2015.

46. Berggreen C. Damage Tolerance of Debonded Sandwich Structures. Ph.D. Thesis, Technical University of Denmark, 2004.

47. Noor AK, Burton WS, Bert CW. Computational Models for Sandwich Panels and Shells. Appl Mech Rev 1996; 49: 155.

48. Frank Xu X, Qiao P. Homogenized elastic properties of honeycomb sandwich with skin effect. Int J Solids Struct 2002; 39: 2153-2188. 